Portland State University

PDXScholar

\title{
Factorial structure of the Hamilton rating scale for depression
}

Kevin Page O'Brien

Portland State University

Follow this and additional works at: https://pdxscholar.library.pdx.edu/open_access_etds

Part of the Clinical Psychology Commons, and the Psychiatric and Mental Health Commons Let us know how access to this document benefits you.

\section{Recommended Citation}

O'Brien, Kevin Page, "Factorial structure of the Hamilton rating scale for depression" (1981). Dissertations and Theses. Paper 3065.

https://doi.org/10.15760/etd.3059

This Thesis is brought to you for free and open access. It has been accepted for inclusion in Dissertations and Theses by an authorized administrator of PDXScholar. Please contact us if we can make this document more accessible: pdxscholar@pdx.edu. 


\title{
FACTORIAL STRUCTURE
}

OF THE HAMILTON RATING SCALE FOR DEPRESSION

\author{
by
}

REVIN PAGE O'BRIEN

A thesis submitted in partial

fulfillment of the requirements for the degree of

\author{
MASTER OF SCIENCE \\ in \\ PSYCHOLOGY
}

Portland State University

1981 
AN ABSTRACT OF THE THESIS OF Kevin Page $0^{\prime}$ Brien for the Master of Science in Psychology presented July 13, 1981.

Tit le: Factorial Structure of The Hamilton Rating Scale for Depression.

APPROVED BY MEMBERS OF THE THESIS COMMITTEE:
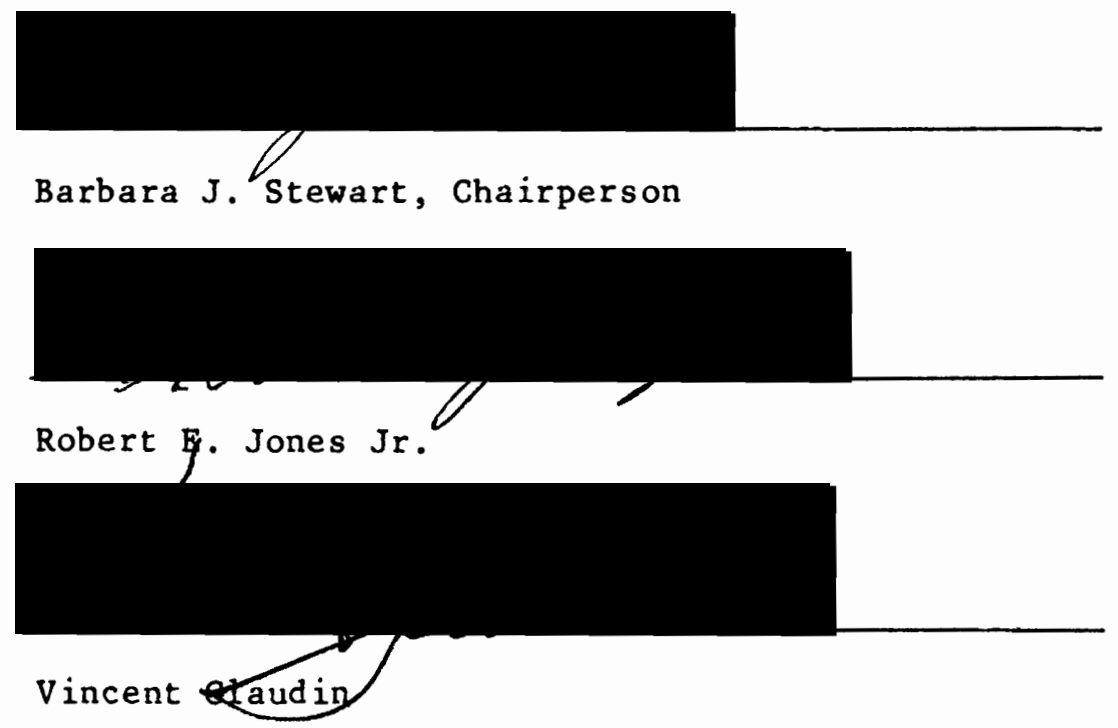

The Hamilton Rating Scale for Depression (HRS), a 17-item observer-rated scale, was first developed in 1960 to assess the severity of depressive symptomatology in patients diagnosed as suffering from depression. The HRS has since demonstrated high inter-rater reliability (with coefficients ranging from .87 to .94), and has proven useful in measuring changes of severity following treatment. 
Since its development, the HRS has been the focus of several factor analytic investigations, four of which attempted to assess the instrument for factorial invariance. Factorial invariance refers to the generalizability or applicability of dimensions developed from one sample to another. While some consensus had been achieved on two factors, one a bipolar factor (i.e., with both positive and negative loadings) contrasting agitation and retardation, the other a general factor with loadings on several of the HRS items, little agreement had been attained on subsequent factors. Three problem areas were identified which may have contributed to the disparate results.

First, inadequate sample size may restrict the range and distort the correlation coefficients, and hence, the factor analysis itself. In two of the studies examined (Hamilton, 1960; Weckowicz et al., 1971) HRS ratings from 52 or fewer patients were employed for the analyses.

Second, the clinical dimensions of depression have been shown to vary with treatment setting (Paykel, Klerman, \& Prusoff, 1970). Upon inspection, considerable differences exist between the samples of the four studies. Hamilton (1960) used British male inpatients, and in 1967 used these same patients in addition to male and female outpatients and patients seen in an acute admission ward. Weckowicz et al. (1971) obtained their HRS ratings from Canadian males treated in a psychiatric unit of a general hospital, while Mowbray (1972) included inpatients, day patients, outpatients, and even a group of non-depressed medical patients serving as controls in his analyses. 
Third variations in the mathematical procedures may influence the outcome of a given factor analysis. While all four studies employed principal components, which placed unity in the main diagonal of the intercorrelation matrix, they differed in their rotational procedures. In two of the studies (Hamilton, 1967; Weckowicz et al., 1971) Varimax rotation was used, while in a third study (Hamilton, 1960 ) rotation was achieved by means of a hand-rotated matrix. In Mowbray's (1971) investigation, Varimax rotation was used, but only the unrotated factors were 1 isted and discussed.

In an attempt to circumvent the methodological deficiencies found in previous studies, the present investigation first performed separate factor analyses on the HRS ratings of two groups created by a random division of a total sample of 365 depressed patients. The 256 females and 109 males all sought treatment from the same private psychiatric clinic, and were administered the HRS one week prior to their participation in an independent antidepressant medication study. The results from the first two analyses suggested that four factors could be replicated across the two samples, a1though a total of six rotated factors emerged for both groups. In addition, the percent total variance accounted for by the set of factors for each group was of approximately the same magnitude (i.e., $40 \%$ ).

When the ratings from the entire sample were factor analyzed in an identical manner as the previous two analyses, five factors emerged that seemed readily interpretable. Four of the factors, labelled sleep disturbance, somatic concerns, gastrointestinal disturbance, and 
dysphoria correlated above .45 with total HRS score. A fifth factor, labelled pathological level of activity correlated just .14 with total score.

Overall, the factors of the present study were considerably less complex from the factors of previous investigations. The bipolar factor contrasting retardation (i.e., slowness of thought and decreased motor activity) and agitation appeared to be confirmed in this study. However, the general factor of severity reported by Hamilton (1967) was not. While the dysphoria factor of the present study shared three items in common with Hamilton's (1967) general factor of severity, its correlation of .67 with total HRS score was considerably less than the .93 correlation reported by Hamilton. Furthermore, three other factors of the present study also correlated substantially with HRS score.

In conclusion, the results of the present study indicate that the HRS can exhibit factorial invariance---i.e., that factors can be replicated across two groups. While the present investigation corrected for many of the methodological deficiencies inherent in previous analyses, one limitation should be noted. To maintain adequate sample size, the HRS ratings of males and females were pooled throughout the analyses. Therefore, caution should be used when generalizing to samples of males, or females alone. 
TO THE OFFICE OF GRADUATE STUDIES AND RESEARCH:

The members of the Committee approve the thesis of

KEVIN PAGE O'BRIEN presented JULY 13, 1981.
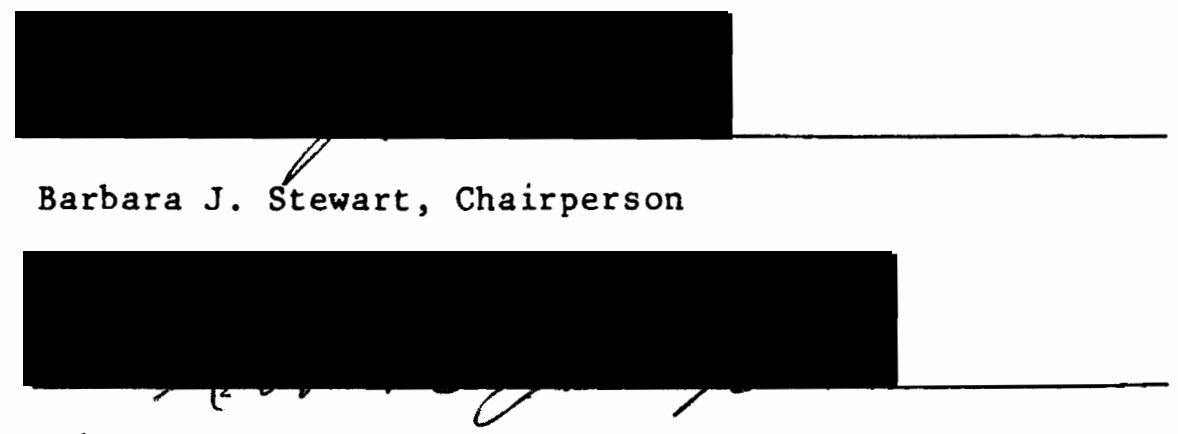

Robert E. Jones Jr.

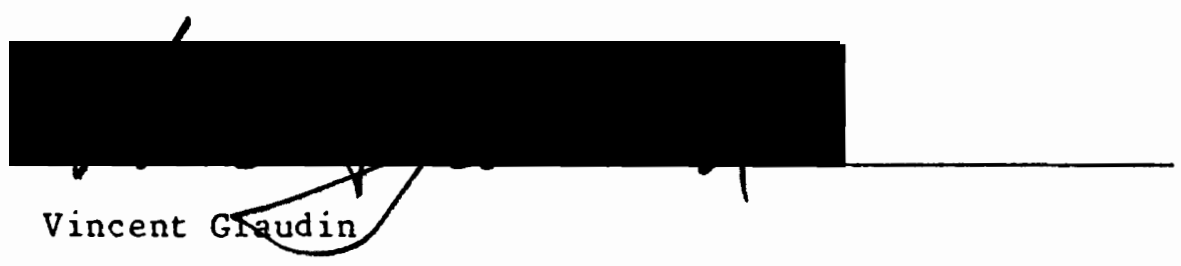

APPROVED :

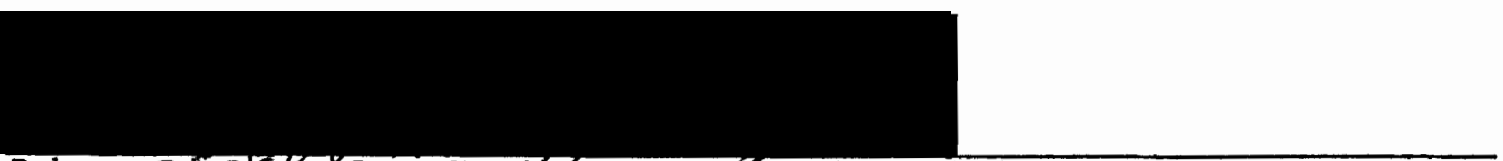

Robert E."Jơnes Jr., Heady Department of Psychology

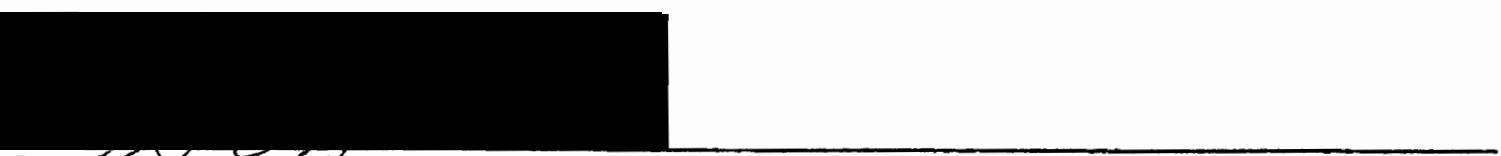

Stanfey E. Rauch, Dean of Graduate Studies and Research 


\section{ACKNOWLEDGEMENTS}

I wish to thank the following persons for their assistance in this study. First, I wish to thank Dr. Vincent Glaudin for generously providing the patients and clinical ratings which were used in this study, as well as for his suggestions and encouragement.

I would also like to thank Dr. Robert E. Jones Jr. for his critique of the study, and for his suggestions on improving the manuscript .

Finally, I wish to give special thanks to my advisor, Dr. Barbara J. Stewart for her assistance in performing the statistical analyses, for her suggestions on improving the experimental design, and for her unfailing encouragement and support. 
TABLE OF CONTENTS

PAGE

ACRNOWLEDGEMENTS

LIST OF TABLES

$\mathbf{v i}$

LIST OF FIGURES. . . . . . . . . . . . . . . . . . .

CHAPTER

I INTRODUCTION . . . . . . . . . . . . . .

II REVIEW OF THE LITERATURE . . . . . . . . . . . .

Attempts to Define Depression. . . . . . .

Assessment of Severity of Depression:

The Hamilton Rating Scale. . . . . .

Factor Analysis. . . . . . . . . . . .

Introduction

Variable Characteristics

Sample Size and Composition

The Intercorrelation Matrix

Unrotated factors

Factor Rotation: Orthogonal and $0 b 1$ ique

Interpretation of the Factors

Factor analytic studies of the HRS . . . . .

Summary of Factor Analytic Research

of the HRS . . . . . . . . . . . .

Variations in Methodology

Focus of the Present Investigation

Hypotheses . . . . . . . . . . . . 
III METHODS . . . . . . . . . . . . . . . . .

Subjects . . . . . . . . . . . . . . .

Procedure. . . . . . . . . . . . . . .

Data Analysis and Demographic Information of Sample. . . . . . . . .

Factor Descriptions for Group 1. . . . . . .

Factor Descriptions for Group 2. . . . . . .

Comparisons of Group 1 and Group 2

Factor Structure . . . . . . . . . .

Factor Descriptions for Total Sample...... Factor Scores

V DISCUSSION . . . . . . . . . . . . . . . .

Factor Structure of HRS. . . . . . . . 55

Methodological Issues. . . . . . . . 59

Limitations of Present Study . . . . . . 63

Conclusions. . . . . . . . . . . . 63

REFERENCES . . . . . . . . . . . . . . . . . . . . . . . 65

SOURCE MATERIAL. • . . . . . . . . . . . . . . . . . . . 68

APPENDICES :

A Intercorrelation Matrices for Group 1 and Group 2. . . . . . . . . . . . . . .

B Unrotated Factors for Group 1 and Group 2. . . . .

C Rotated Factors for Group 1 and Group 2. . . . . .

D Intercorrelation Matrix for Entire Sample. . . . .

E Unrotated Factors for Entire Sample. . . . . . . .

F Rotated Factors for Entire Sample. . . . . . . . . 
I A Listing of the 21 items of the Hamilton Rating Scale for Depression . . . . . . . . .

II Rotated Factors of Three Factor Analytic Studies of the HRS: Hamilton (1960), Hamilton (1967), and Weckowicz, Cropley, and Muir (1971). ....

III Unrotated Factors of the Mowbray (1972) Factor Analytic Study of the HRS. . . . . . . .

IV A Comparison of the Present Investigation to Four Previous Factor Analytic Studies of the HRS. . .

V Demographic Data for Group 1 and Group 2.......

VI Factor Descriptions, HRS Items, and Fact or Loadings for Group 1. . . . . . . . . . . . .

VII Factor Descriptions, HRS Items, and Factor Loadings for Group 2. . . . . . . . . . . .

VIII Factor Descriptions, HRS Items, and Factor Loadings for Entire Sample. . . . . . . . . . . 


\section{LIST OF FIGURES}

FIGURE

PAGE

1. Distribution of HRS total scores for Group 1 and Group 2. . . . . . . . . . . . . . 


\section{INTRODUCTION}

Recently, it has been estimated that each day one in seven Americans suffer from mild depression (Coleman, 1976). In another similar report, regarding a survey of a specific geographical area outside the United States, it was estimated that 3.9 percent of the population over 20 years old suffered from some kind of depression (Sorenson \& Stromgren, 1961). While it may prove difficult to accurately assess the incidence of depression at any one time, millions seek some form of treatment each year---one estimate reports that over four million Americans are treated with antidepressant medication annually, and that 60,000 individuals have depressions so severe that they end in suicide ("Breaking the Chains of Depression", 1976). An important factor then both in research and clinical practice involves a clear understanding of the underlying structure of depression, as well as an ability to assess the severity of a depressive episode. 
Depression, or "melancholia" as it was called by early writers was first described in detail as early as the Fourth century B.C. by Hippocrates. However, even until recently it has been noted that: "In the case of the depressive disorders, the problems of diagnosis and judgment of depth are perhaps more difficult than in any other form of mental illness" (Wechsler, Grosser, \& Busfield, 1963; p.334). In a specific attempt to elucidate the causes of disagreement among diagnosticians, Ward, Beck, Mendelson, Mock, and Erbaugh (1962) found that $5 \%$ of the disagreement among psychiatrists was attributable to fluctuations in the clinical state of the patient; $37 \%$ was due to inconsistencies on the part of the psychiatrists; and $58 \%$ of the lack of consensus was due to inadequacies of the nosological system.

Even now depression can be viewed in at least four different ways: (1) as a normal, transient, lowering of mood similar to sadness or gloom; (2) as a clinical syndrome consisting of depressed mood, feelings of worthlessness, difficulty in thinking, and psychomotor retardation; (3) as a fundamental biological disturbance, or disease; or (4) as a reaction to sudden loss, or stress. Furthermore, disagreement still exists as to whether depressions are a variant of a single, underlying disorder, or whether they are clinically distinct entities (Wechsler, et al., 1963). The picture is further obscured by the presence of numerous classification systems, each of which 
subdivides the population of depressed individuals differently as evidenced by such distinctions as primary/secondary, neurotic/psychotic, agitated/retarded, and endogenous/reactive, to name just a few.

Assessment of Severity of Depression-The Hamilton Rating Scale

As a consequence of growing dissatisfaction with the utility of various nosological systems for categorizing depression, many investigators began exploring alternate methods for identifying those patients with depressive symptomatology. One apparently successful approach involved assessment of the depth of severity of depression without regard to "type" or specific diagnosis.

Since 1960 , many rating scales have appeared that measure or quantify the severity of depression, but three have received particularly wide attention: (1) the Hamilton Rating Scale for Depression (HRS) (Hamilton, 1960); (2) the Beck Inventory of Depression (BDI) (Beck, Ward, Mendelson, \& Erbaugh, 1961); and (3) the Self-rating Depression Scale (SDS) (Zung, 1965). The two latter instruments, the BDI and SDS, are self-rating scales, and as such require that patients rate themselves on a variety of symptoms. While these inventories are easy to administer and require little time of the clinician, they have been criticized for being unreliable and not useful in assessment of severely ill or semi-literate patients (Hamilton, 1960; Carroll, Fielding, \& Blashki, 1973). Furthermore, according to Anastasi (1968) and Nunnally (1968), social desirability 
is a major contributor to response bias in self-report instruments, especially those measuring personality traits.

The HRS on the other hand, is an observer-rated scale, completed after a semi-structured interview by a skilled rater such as a psychiatrist or clinical psychologist. The initial scale had 17 items, nine of which were graded on a 0 to 2 continuum, the remaining eight on a 0 to 4 continuum. The items were labelled as follows:

(1) Depressed mood; (2) Feelings of Guilt; (3) Suicide;

(4) Insomnia-early; (5) Insomnia-middle; (6) Insomnia-late; (7) Work and Activities; (8) Retardation; (9) Agitation; (10) Anxiety-psychic; (11) Anxiety-somatic; (12) Somatic symptoms-gastrointestinal;

Somatic symptoms-general; (14) Genital symptoms; (15) Hypochondriasis; (16) Loss of weight; and (17) Loss of Insight (See Table I for complete listing of items).

Later, Hamilton included four additional items on the same form, but did not use them when calculating total score. Diurnal variation (18), while not contributing to the overall severity score per se, was included because it indicated type of illness---depressions that were described as being worse in the morning but better in the evening were typically assumed to be endogenous, a type of depression thought to be biological in nature, relatively independent of environmental influences and with probable genetic components. Considered to occur too infrequently to be included in the rating of symptom severity, but thought by Hamilton to be important for research purposes the last three items added to the scale were: (19) Derealization and 
TABLE I

THE HAMILTON RATING SCALE FOR DEPRESSION

\section{FOR EACH ITEM CIRCLE THE NO. NEXT TO THE RESPONSE THAT BEST CHARACTERIZES THE PATIENT. \\ 1. DEPRESSED MOOD (Sedness, Hopaless, Helpless, Worthless)
O. Absent
1. These feling states indicated only on quastioning
2. These feeling states epontaneously reportied verbelly
3. Communicates feeling states nonvertelly - i.e., through facial expression, posture, voice, and tendency to weep
4. Patient reports VIRTUALLY ONLY these feeling states in his sponteneous verbel and non-verbel communication

2. FEELINGS OF GUILT
0. Abeent
1. Self-reproach, feels he ha let people down
2. Idees of guilt or rumination over pest errors or sinful deeds
3. Present illness is a punishment. Delusions of quilt
4. Hears eccusatory or denuncietory wices and/or experiences threatening visual hallucinations

3. SUICIOE
0. Abeent
1. Feels life is not worth living
2. Wishes he were dead or any thoughts of possible death to alf
3. Suicide ideses or gesture
4. Attempts at suicide (any serious uttempt rates 4)

4. INSOMNIA EARLY
O. No difficulty falling asieep
1. Complains of occetiond difficulty falling saleep - i.e., more then 1/2 hour

2. Complains of nightly difficulty falling waleep

5. INSOMNIA MIDDLE
O. No difficulty
1. Patient complains of being restless and disturbed during the night
2. Waking during the night - any getting out of bed rates 2 (except for purposes of voiding)

6. INSOMNIA LATE
O. No difficulty
1. Waking in early hours of the morning but goes beck to sleep

2. Unable to fall asleep egain if gets out of bed

7. WORK AND ACTIVITIES

0. No difficulty

1. Thoughts and feelings of incapacity, fatigue or weskness related to activities, work or hobbies

2. Loss of interest in ectivity, hobbies or work - either directly reported by petient, or indirect in listlessnes, indecision and vacillation (feels ha has to push ealf to work or activities)

3. Decrease in ectual time spent in activities or decreas in productivity. In hospital, rete 3 if pertient does not spend at least three hours a day in activities (hospital job or hobbies) exclusive of ward chores

4. Stopped working because of present illness. In hospital, rete 4 if patient engeges in no ectivities except werd chores, or if patient fails to perform ward chores unassisted

8. RETARDATION (Slowmess of thought and speech, impaired ability to concentrate, decreased motor activity)
O. Normal speech and thought
1. Slight retardation at interview
2. Obvious retardation at interviow

3. Interview difficult

4. Complete stupor

9. AGITATION
o. None
1. "Playing with" hands, hair, etc.
2. Hand-wringing, nailbiting, hair-pulling. biting of lips

10. ANXIETY.PSYCHIC
0 . No difficulty
1. Subjective tension and irritability
2. Worrying about minor matters
3. Apprehensive attitude epperent in face or speech
4. Fears expreseed without questioning

11. ANXIETYSOMATIC
0. Absent
1. Miid
2. Moderate
3. Severe
4. Incapecitatine

Physiological concomitants of enxioty, such as:

Gastro-intestinal - dry mouth, wind, indigestion, dierrhes, cramps, belching

Cardio-vescular - pelpitations, headeches

Respiraton - hyperventilation, sighing

Urinary frequency

Sweating 
TABLE I (continued)

THE HAMILTON RATING SCALE FOR DEPRESSION

FOR EACH ITEM CIRCLE THE NO. NEXT TO THE RESPONSE THAT BEST CHARACTERIZES THE PATIENT. 12. SOMATIC SYMPTOMS-GASTRO-INTESTINAL

0. None $\quad$ 1. Loss of appetite but eating without staff encouregement. Heav feelings in sbdomen

2. Difficulty eating without staff urging. Requests or requires laxatives or medication for bowels or medication for G. I. symptoms.

13. SOMATIC SYMPTOMS-GENERAL

O. None 1. Heaviness in limbs, back or head. Backeches, headeche, muscle aches. Loss of energy and fatigability

2. Any clear-cut symptom rates 2

14. GENITAL SYMPTOMS (Symptoms such es: loss of libido, menstrual disturbances)
O. Absent
1. Mild
2. Sovere
9. Not ascertained

15. HYPOCHONDRIASIS
O. Not present
1. Self-absorption (bodily)
2. Preoccupation with health
3. Frequent complaints, requests for help, etc.
4. Hypochondriacal delusions

16. LOSS OF WEIGHT

\section{A. WHEN RATING BY HISTORY}

0. No weight loss

1. Probable weight lose essocieted with present illness

2. Definite (according to patient) weight loss

8. ON WEEKLY RATINGS BY WARD PSYCHIATRIST, WHEN ACTUAL WEIGHT CHANGES ARE MEASURED:

0. Less than $1 \mathrm{lb}$. weight loss in week

1. Greater than $1 \mathrm{lb}$. woight loss in woek

2. Greater than 2 lb. weight loss in woek

17. INSIGHT
O. Acknowledges being depressed and ill
1. Denies being ill at all

2. Acknowledges illness but attributes cause to bed food, climate, overwork, virus, need for rest, etc.

18. DIURNAL VARIATION

CHECK EITHER AM. OR P.M. AND CIRCLE SEVERITY OF VARIATIONL

$\begin{array}{ll}\text { A.M. } & \text { P.M. } \\ \text { (1) } & \text { (2) }\end{array}$

0. Abesnt

1. Mild

If symptoms are worse in the morning or evening

ง. Mild note which it is and rate severity of variation

2. Severe

19. DEPERSONALIZATION AND DEREALIZATION (Such as: feelings of unreality, nihilistic ideas)
O. Absent
1. Mild
2. Moderate
3. Severe
4. Incapacitating

20. PARANOID SYMPTOMS
o. None
1. Mildly
cuspicious
2. Moderately suspicious
3. Ideas of reference
4. Delusions of reference and persecution

21. OBSESSIONAL AND COMPULSIVE SYMPTOMS
0. Absent
1. Mild
2. Severe

INVESTIGATOR'S SIGNATURE: 
Depersonalization; (20) Paranoid symptoms; and (21) Obsessional symptoms.

Since its appearance, the HRS has proven to be an invaluable clinical and research tool in the assessment of severity of depression and change during treatment (Dykstra, 1969; Hamilton, 1960; Knesevich, Biggs, Clayton, \& Ziegler, 1977; Rose, Leahy, Martin, \& Westhead, 1965; Waldron \& Bates, 1965), as well as in factor analytic studies attempting to differentiate types of depression or symptom clusters (Hamilton \& White, 1959; Mowbray, 1972; Weckowicz, Cropley, \& Muir, 1971). It has also been found to exhibit close concordance with other depression rating scales (Bailey \& Coppen, 1976; Davies, Burrows, \& Poynton, 1975; Schwab, Bialow, \& Holzer, 1967). In addition, extensive research by several independent investigators indicates that the HRS possesses good inter-rater reliability, with reported reliability coefficients that range from .87 to .94 (Bech, Gram, Dein, Jacobsen, Vitger, \& Bolwig, 1975; Davies, et al., 1975; Dykstra, 1969; Hamilton, 1960; Knesevich, et al., 1977; Waldron \& Bates, 1965).

\section{Factor Analysis}

A frequent question that arises in the field of measurement is whether or not a given instrument measures the same characteristic in one sample as it does in another different sample. One problem that is frequently encountered in personality research is whether or not a set of scales valid for males is also valid for females (Derogatis, Lipman, Covi, \& Rickels, 1971). In addition, within a particular scale some items may correlate substantially with each other, while 
other items or clusters may not correlate well at all. One technique that facilitates in the evaluation of the underlying structure or dimensions of a scale is the procedure of factor analysis.

Factor analysis in its most simple form, provides a method for condensing a large variety and number of measurements or observations into a smaller, more general set of dimensions or "factors", with a minimum loss of overall information (Cattel1, 1965a; Rumme11, 1968). While it has become increasingly popular since its initial development by Spearman in 1904, factor analysis has been criticized for being poorly understood by many of those who use it (Comrey, 1973).

Although extremely helpful when used properly, factor analysis has all too often been called upon to rescue poorly designed or unplanned research (Comrey, 1973), and is frequently performed with data not suitable for this type of procedure (Creasy, 1959). Therefore, when comparing the results of investigations that have relied on factor analytic methods, it becomes of paramount importance to understand the techniques involved, and to appreciate how variations in those techniques may differentially affect the type and number of factors that subsequently emerge. Under the general rubric of factor analysis, at least six distinct procedures may be identified, each of which can be performed in a variety of ways. First, serious consideration must be focused on the data variables for these ultimately define the dimensions that emerge from a given analysis. If a factor structure is hypothesized to exist, 
then enough variables or "markers" need to be included to identify each factor that is expected to emerge. Three such variables per factor are considered to be a minimum (Comrey, 1973). In addition, the measurement characteristics of the variables selected are also important. Ideally, all variables would be continuous and have linear relationships with each other. Sometimes dichotomous variables or variables having non-1inear relationships are used which produce significant distortions in the correlation coefficients, and as a result, in the factor loadings themselves.

Second, careful attention must be directed to the selection of subjects, of which sample size is of prime concern. In his book, $A$ First Course in Factor Analysis (1973), Andrew Comrey provided a rough estimate for evaluating the adequacy of sample size: "50-very poor; 100-poor; 200-fair; 300-good; 500-very good; 1000-excellent." Another estimate suggested by Nunnally (1968) recommends that ten subjects be used for every variable selected. For example, if a researcher wished to examine the underlying dimensions measured by a 12-items scale, at least 120 subjects would be required for the analysis according to Nunnally's criterion. Failure to employ sufficient sample size, which can suppress the magnitude of the correlation coefficients (Comrey, 1973), may produce factors which are unreliable or prevent the emergence of "real" factors due to possible restriction of range (Comrey, 1973; Guertin \& Bailey, 1970).

Another consideration in selecting subjects for a factor analytic study is sample composition and its influence on the 
resultant factor structure. In an investigation of the effects of treatment setting on clinical features of depression, significant differences on age, number of previous hospitalizations, and severity of depression were obtained between outpatient, inpatient, day patient, and emergency treatment patient groups (Paykel, Klerman, \& Prusoff, 1970). In many cases a continuum of severity was observed; outpatients and inpatients occupying the extremes, with day patients and emergency treatment patients in the intermediate positions. The implications of this study confirm the notion that depressed individuals constitute a diverse, heterogenous group, and that the underlying structure or clinical dimensions of depression may vary from setting to setting, at least when examined by the above criteria. The third procedure to consider, a mathematical one, involves correlating all data variables with each other, i.e., computation of the intercorrelation matrix. While many correlation coefficients have been developed to deal with the various types of data (such as continuous, dichotomous, continuous but dichotomized, etc), the Pearson product-moment correlation coefficient $(\underline{r})$ is usually the one of choice, especially now that high speed computers have been programmed to carry out the once tedious computations. Use of other coefficients such as the phi, point biserial, biserial, and tetrachoric in factor analysis was primarily restricted to precomputer research where investigators sought to reduce the laborious task of manual computations characteristic of the Pearson $\underline{r}$ (Comrey, 1973). 
The next step in the computation of the intercorrelation matrix, deciding on what values are to be used in the diagonal cells, can be achieved in one of two ways: The first method, called "principal components analysis" places one's (unity) in the diagonal cells; the second method called "principal factor analysis" places some type of estimate, usually less than one, in the diagonal. The first method produces communalities (the sum of the squared factor loadings for each variable) which are equal to one. However, if the diagonal values exceed the actual communalities of the variables, then extra error and specific variance are extracted and treated as common variance. This results in factors that are not just composed of common variance, but factors that consist of comnon, error, and specific variance mixed in some indeterminate way. For this reason, many investigators choose to use communality estimates for the diagonal values (Comrey, 1973). One of the most widely employed estimates, the squared multiple correlation or SMC, is computed by summing the squared correlations of a given variable with all other variables. While this method may produce estimates which are too low, several "cycles" or additional factor analyses can be performed until the extracted communalities are equal to the initial communality estimates. This process of repeating a given factor analysis over and over is called iteration. According to Comrey (1973), 10 to 15 iterations are usually sufficient to produce stable communalities. The fourth procedure, extraction of the unrotated factors, identifies distinct (uncorrelated) patterns of relationships. 
Usually factor extraction is performed in a step-wise fashion that maximizes the amount of variance accounted for by each successive factor, until the amount of variance explained by later factors becomes very small, or negligible. Three approaches exist which serve as guidelines in the decision when to stop the factor extraction process: mathematical concepts, statistical evaluation, and factor structure criteria (Cattel1, 1965a), al though there remains considerable disagreement on the criteria for determining the exact number of factors to be extracted for any given set of data (Rummel, 1968).

The fifth procedure, rotation of the factors, attempts to identify not just general patterns as in the unrotated case, but distinct clusters of relationships---if they exist. While several methods are available, rotation procedures can be classified into one of two general types: orthogonal and oblique, which differ essentially in that they yield uncorrelated and correlated factors, respectively. Several computer programs have been constucted to perform orthogonal rotation, of which three have enjoyed particularly wide use: (1) Varimax (Kaiser, 1958); (2) Quartimax (Wrigley, Saunders, \& Newhaus, 1958); and Oblimax (Pinzka \& Saunders, 1954). The fundamental assumption in orthogonal rotation asserts that the factors, or dimensions that they are supposed to represent, are independent; hence, no variable should have a very high loading on more than one factor.

oblique rotation on the other hand, searches for both correlated and uncorrelated clusters of relationships in the variables, i.e., it 
does not restrict a variable with high loading on one factor from also having a high loading on another factor. Basically, oblique rotation procedures result in two types of output: The primary factor pattern matrix yields loadings which define the separate factors and each variable's involvement in the particular pattern; however, the loadings cannot be interpreted as true correlation coefficients. The primary factor structure matrix, while not clearly displaying the patterns of relationships among the variables, does however, yield loadings that can be interpreted as true correlations between variables and factors.

Some investigators who favor oblique rotation over orthogonal methods maintain that orthogonality in nature represents a special, rather than usual case (Cattel1, 1965b; Rummel, 1968). However, orthogonal solutions are advantageous because they are easier to report, require less computation, and frequently yield solutions highly similar to the more time consuming and complex oblique procedures (Comrey, 1973). Moreover, when non-orthogonal methods are employed one must determine how much obliquity is to be allowed among the factors, i.e., setting limits on the magnitude of the correlations between the factors.

The sixth procedure, interpretation of the factors, must address several important questions, a few of which are: "How does the factor relate to previous taxonomic systems of interest in the domain under investigation? ... How firmly established is the factor 
identification? ... Will other studies be needed to identify more completely just what the factor is?" (Comrey, 1973; p.227). While there are no easy answers to these questions, general guidelines exist which facilitate the interpretation process.

First, the magnitude of the factor loadings indicates the degree to which the variance of each variable can be attributed to the specific factor; higher loadings indicate greater similarity between the variable and the factor in question. While most investigators would agree on what constitutes a high loading (for example .70 or above), disagreement still persists on the significance attached to low or moderate loadings, although \pm .30 has often been employed as the lower cut-off point'(Comrey, 1973).

Second, unidimensional variables make description of a factor easier than when using multidimensional or complex variables in the analysis. For example, it would be relatively easy to describe a factor which had loadings on loss of weight, loss of appetite, and gastrointestinal disturbance compared to the task of describing a factor with high loadings on such items as "orality", "introjected anger", and "loss of ego strength".

Third, as the number of variables with high loadings per factor increases, it becomes easier to distinguish and hypothesize what a factor likely represents. Herein lies the importance of including a sufficient number of "marker" variables with which to delineate a given dimension, since variable selection may over- or under-represent important facets of a particular factor. 
Fourth, when naming factors an investigator may adopt one of three strategies: (a) symbolic labels, which carry no meaning other than that of differentiating one factor from another; (b) descriptive labels, which attempt to relate several variables under a general theme; and (c) causal labels, which attempt to identify some underlying phenomenon which could account for the particular pattern of variables (Rummel, 1968).

One error that frequently occurs when examining the results of two different factor analyses is the comparison of factors solely by name, rather than by actual content, i.e., by the variable loadings. While two factors may share commom names, in fact they may be quite dissimilar when scrutinized on the basis of the type of variables involved.

Finally, other than a replication study, few methods exist which enable direct comparison of factor analytic results obtained from different investigations. While one objective technique has been developed by Ahmavara (1954), it has not yet achieved wide acceptance. Factor Analytic Studies of the HRS

The first factor analytic investigation of the HRS appeared with the initial presentation and description of the scale items (Hamilton, 1960). In this study ratings from 49 depressed, British, male inpatients were used to construct the intercorrelation matrix, which was factor analyzed by the principal components method (with ones in the diagonal) which yielded six unrotated factors. The first three factors were rotated by an orthogonal matrix designed to approximate 
the "best fit" for simple structure, while the fourth factor was left unrotated as it already had several near zero loadings (see Table II for listing of rotated factors). The remaining two unrotated factors were not rotated because they were considered too unstable to warrant further description.

The first factor, labelled "retarded depression" had loadings greater than .30 on six items: Feelings of Guilt; Depressed mood; Suicide; Genital symptoms (e.g., loss of libido, or menstrual disturbance); Retardation in speech and behavior; and Loss of Insight. In his discussion, Hamilton made note of the close correspondence between the items loading on this factor and the classical description of retarded depression.

Tentatively labelled "agitated depression", the second factor contained loadings greater than .30 on nine items: Somatic sypmtoms-gastrointestinal, Insomnia-early, Loss of weight, Insomia-late, Work and Activities, Insomnia-middle, Agitation, Hypochondriasis, and Loss of insight. The equivocal nature of this factor, according to Hamilton, was due to the fact that both anxiety items (somatic and psychic) failed to emerge on this factor in the presence of the Agitation item.

The third factor, which Hamilton thought might be an "anxiety reaction" dimension, emerged with three loadings greater than .30 and three loadings less than -.30 . The items with positive loadings included Anxiety-psychic, Anxiety-somatic, and Agitation; the negative 


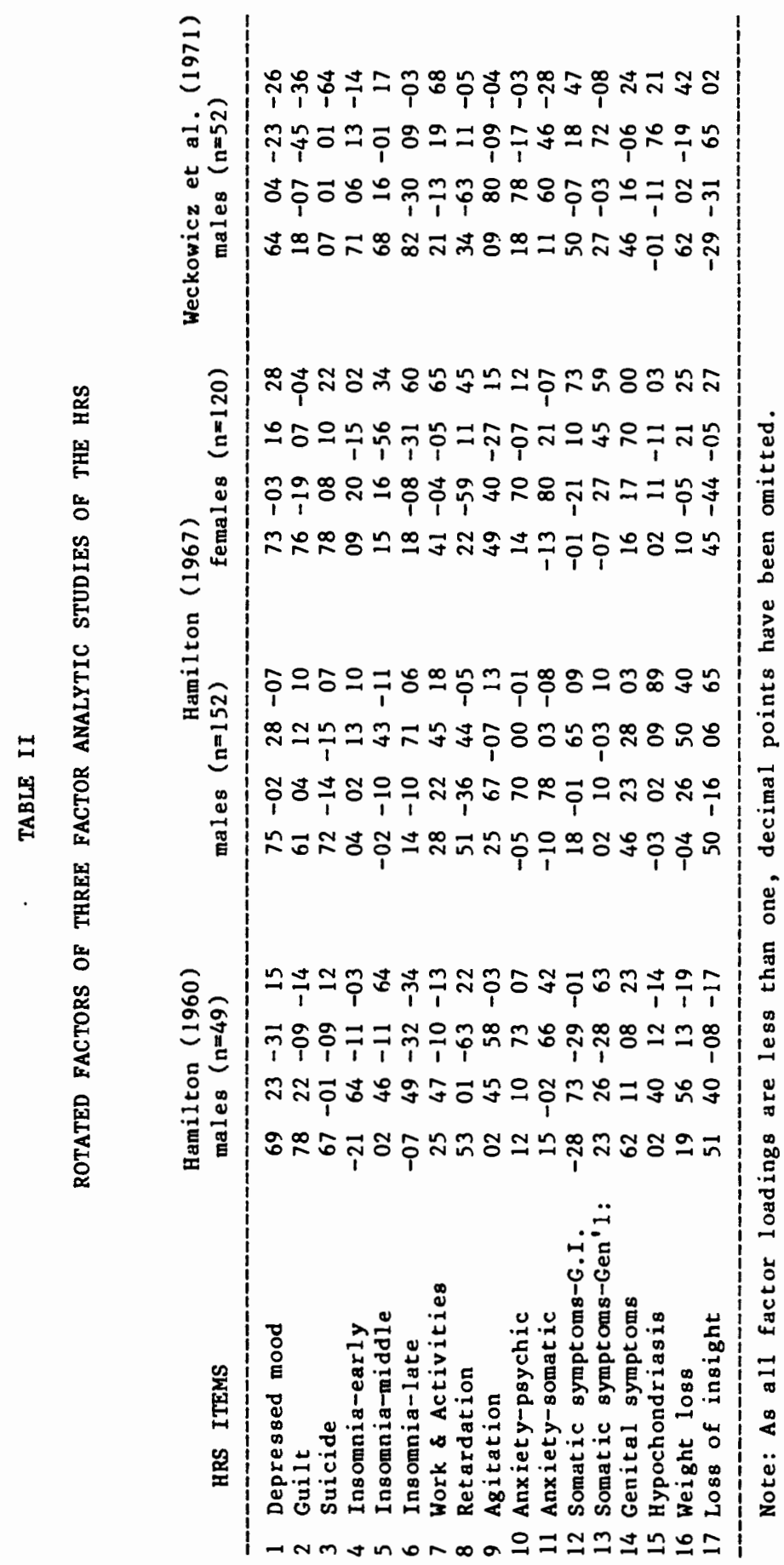


loadings emerged on Retardation (e.g., slowness in speech and behavior), Insomnia-delayed, and Depressed mood.

The fourth factor, left unrotated and unnamed "because it did not bring any clinical pattern to mind", contained three items with loadings above .30 (Insomnia-middle, Somatic symptoms-general, and Anxiety-somatic), and one item with a loading less than -.30 (Insomnia-delayed).

The factor analysis described above attempted to delineate the underlying structure of depression as measured by the HRS; however, over-interpretation of these findings must be avoided in view of the extremely small sample size $(N=49)$, "very poor" by Comrey's criteria, and the absence of pertinent demographic data on the patients used. In fact, Hamilton himself cautioned against over-generalization when he wrote of his 1960 study that, "(this) must be regarded as little more than a preliminary report, intended to arouse interest and encourage use of and development of such a scale" (Hamilton, 1967; p. 278).

In an effort to confirm his earler results, Hamilton (1967) factor analyzed the HRS ratings of 152 males and 120 females obtained from a variety of settings. For the male sample, Hamilton used the 49 patients from his earlier study, an additional 39 patients obtained in the same manner as the first group, 15 patients seen in an acute admission ward of a mental hospital, and a final group of 49 males containing proportionally more outpatients than the first two groups. 
No demographic data or breakdown by treatment setting was provided for the 120 females.

Since Hamilton obtained significant differences between males and females on seven of the HRS items ( $\# 1, \# 4, \# 7, \# 8, \# 9, \ldots 10$, and $\# 13)$, as well as on incidence and in mean age of onset of the first episode of depression for hospitalized patients, he performed two separate factor analyses by the principal components method which placed ones in the main diagonal of the intercorrelation matrix. This is the same procedure that he employed in the earlier 1960 analysis.

As in the 1960 investigation, six unrotated factors emerged for the male sample, as well as for the female sample. However, the two studies differed in their rotational procedures: the 1960 study graphically rotated three factors by trial and error until close approximation to simple structure was achieved; the 1967 study employed Varimax rotation (Kaiser, 1958). While six factors were rotated for each of the male and female samples, only the first four were considered stable enough to warrant description (see Table II). The first factor of the male sample was described by Hamilton as a "General Factor of Depressive Illness" measuring severity, which produced loadings greater than .30 on six items: Depressed mood, Suicide, Guilt, Retardation, Loss of insight, and Loss of libido. While exhibiting close concordance with the first factor of the 1960 study, a correlation of .93 between this factor and HRS total score supported Hamilton's belief that it was a general factor of severity rather than a "retarded depression" factor as first described. As 
illustrated by Hamilton's choice of the label "retarded depression" in his first study, one common mistake made in factor analysis is to incorrectly assume that a factor represents a nosological entity. The purpose of a psychiatric diagnosis is to place the patient into a particular category, i.e., a patient may be diagnosed as suffering from schizophrenia or an anxiety neurosis, but (theoretically) not both. On the other hand, a patient can be described by any number of dimensions in a given orthogonal factor analysis; since the factors are independent, a high score on one factor does not preclude a high score on another.

Factor two of the male sample, identified as a bipolar dimension labelled "Retarded vs Agitated" depression, had three loadings above .30 on Anxiety-somatic, Anxiety-psychic, and Agitation, with one loading less than -.30 on Retardation. This factor resembled factor 3 of the 1960 investigation, but negative loadings on Depressed mood and Insomnia-delayed failed to appear in this factor as in the earlier analysis.

The third factor of this sample, characterized by six loadings above .30 (Insomnia-delayed, Somatic symptoms-gastrointestinal, Loss of weight, Work and Activities, Retardation, and Insomnia-middle) exhibited some similarity to factor 2 of the 1960 study, but discrepancies on five variables with loadings greater than or equal to .30 made strict comparisons difficult.

The fourth factor, with loadings above .30 on Hypochondriasis, Loss of insight, and Loss of weight, formed a pattern suggestive of 
emotional instability according to Hamilton. However, no comparable pattern emerged in the earlier 1960 investigation.

For the female sample, the first factor was labelled a general factor of depression measuring severity and appeared very similar to that of the male patients. Six items with loadings greater than .30 emerged on this factor: Suicide, Feelings of guilt, Depressed mood, Agitation, Loss of insight, and Work and Activities.

The second factor of the female sample contained three items with loadings above .30 (Anxiety-somatic, Anxiety-psychic, and Agitation) and two items with loadings less than -.30 (Retardation and Loss of insight). This bipolar factor appeared to bear close resemblance to the bipolar factor of the male sample which Hamilton thought contrasted "Retarded vs Agitated" depression.

Factor 3 for the female sample contained loadings greater than .30 on two items, Loss of 1 ibido and Somatic symptoms-general, and contained two items with loadings less than -.30 (Insomnia-middle, and Insomnia-delayed). This dimension did not appear in the male sample.

The fourth factor, on the other hand, exhibited a good deal of similarity with the third factor of the male analysis, and produced six items with loadings above . 30 : Somatic symptoms-gastrointestinal, Work and Activities, Insomnia-delayed, Somatic symptoms-general, Retardation, and Insomnia-middle.

While Hamilton attempted to shed further light on the internal structure of the HRS, several shortcomings limit the generalizability of the 1967 findings: First, the male sample included 49 patients 
whose HRS data were used in the previous 1960 analyses, which limits the degree to which the latter investigation can be viewed as a strict replication study. Second, analyses of variance on the four groups of male patients across each of the 17 HRS items yielded eight $\underline{F}$ ratios significant at, or below the .01 leve1---that is, the groups cannot be considered as representing the same population of depressed males. Third, insufficient demographic data for both the male and female samples limits the degree to which they may be compared to each other, as well as with other depressed samples. While Hamilton (1967) obtained differences between males and females on several variables, lack of demographic information precludes attributing these variations to sex differences alone; some of the discrepancies may be due to differences in treatment setting.

In another attempt to replicate Hamilton's 1960 findings and test the HRS for factorial invariance on another depressed sample, Weckowicz, Cropley, \& Muir (1971) administered the HRS to 52 depressed males receiving treatment in a psychiatric unit of a general hospital. A principal components analysis was performed, as in the Hamilton investigations, which yielded four unrotated factors. These were then rotated by Varimax procedure (see Table II for listing of rotated factors).

A comparison of the rotated factors obtained in this study with those of the Hamilton (1960) investigation led the authors to conclude "... that there is very little similarity between the sets of factors ... (and that) there is no one to one matching of the factors 
obtained by Hamilton and those of the present study." (Weckowicz et al., 1971; p.31). However, compared in a more lenient fashion, one factor of the Weckowicz et al. study seemed similar to a factor in Hamilton's analysis (the "Anxiety reaction factor"). Five of the six items which described this factor in Hamiltons's 1960 study were similarly included in the Weckowicz et al. analysis: three items had positive loadings (Agitation, Anxiety-psychic, and Anxiety-somatic); and two items had negative loadings (Retardation and Insomnia-late). One additional item, Loss of insight, with a loading of approximately -.30 also appeared on this factor in the Weckowicz et al. study. That no further congruence appeared between the factors of the these two studies may be attributed to several methodological variations: First, both studies employed very small samples, each obtained from a different country (i.e., one from Great Britain and one from Canada). Second, Hamilton graphically rotated his factors by trial and error until a good approximation to simple structure had been achieved, while Weckowicz and associates employed Varimax rotation. Third, both studies included scant demographic information and little data regarding diagnosis, which obviates any direct evaluation of the samples for similarity. Fourth, the investigations differed in the number of factors initially extracted: Hamilton produced six unrotated factors prior to rotation, while Weckowicz and associates extracted just four unrotated factors. Finally, the appropriateness of the Weckowicz, Cropley, and Muir attempt to replicate Hamilton's 1960 study rather than the 1967 investigation 
must be questioned since the earlier Hamilton study was considered to be only a "preliminary report", not a definitive analysis.

In a more recent investigation that attempted to replicate the factors of the 1967 study by Hamilton, Mowbray (1972) obtained HRS ratings for 213 females and 134 males which covered a wide range of severity. Included among the sample were 18 patients seen in general practice, as well as hospitalized inpatients, outpatients, and day patients. Concerned that a restriction of range could reduce the magnitude of the correlations and obscure the emergence of a general factor of depression measuring severity, Mowbray included mildly depressed and non-depressed subjects. Following Hamilton's strategy, males and females were analyzed separately, although the mean HRS total scores for the two sexes were nearly equal, and the two distributions approximated normal, be11-shaped curves.

A principal components factor analysis was performed which yielded six unrotated factors for each sex (see Table III). While the factors were reportedly rotated by Varimax procedures, these results were not included in the study's tables or discussion, although Mowbray did compare his unrotated factors to the unrotated factors obtained by Hamilton in 1967. Since the usual objective of factor analysis is the interpretation of meaningful, or rotated factors (Rummel, 1968), only studies describing rotated factors have been considered in detail throughout this paper. However, considering the unrotated factors for just a moment, Hamilton's general factor of depressive illness was, for the most part, confirmed by Mowbray in 


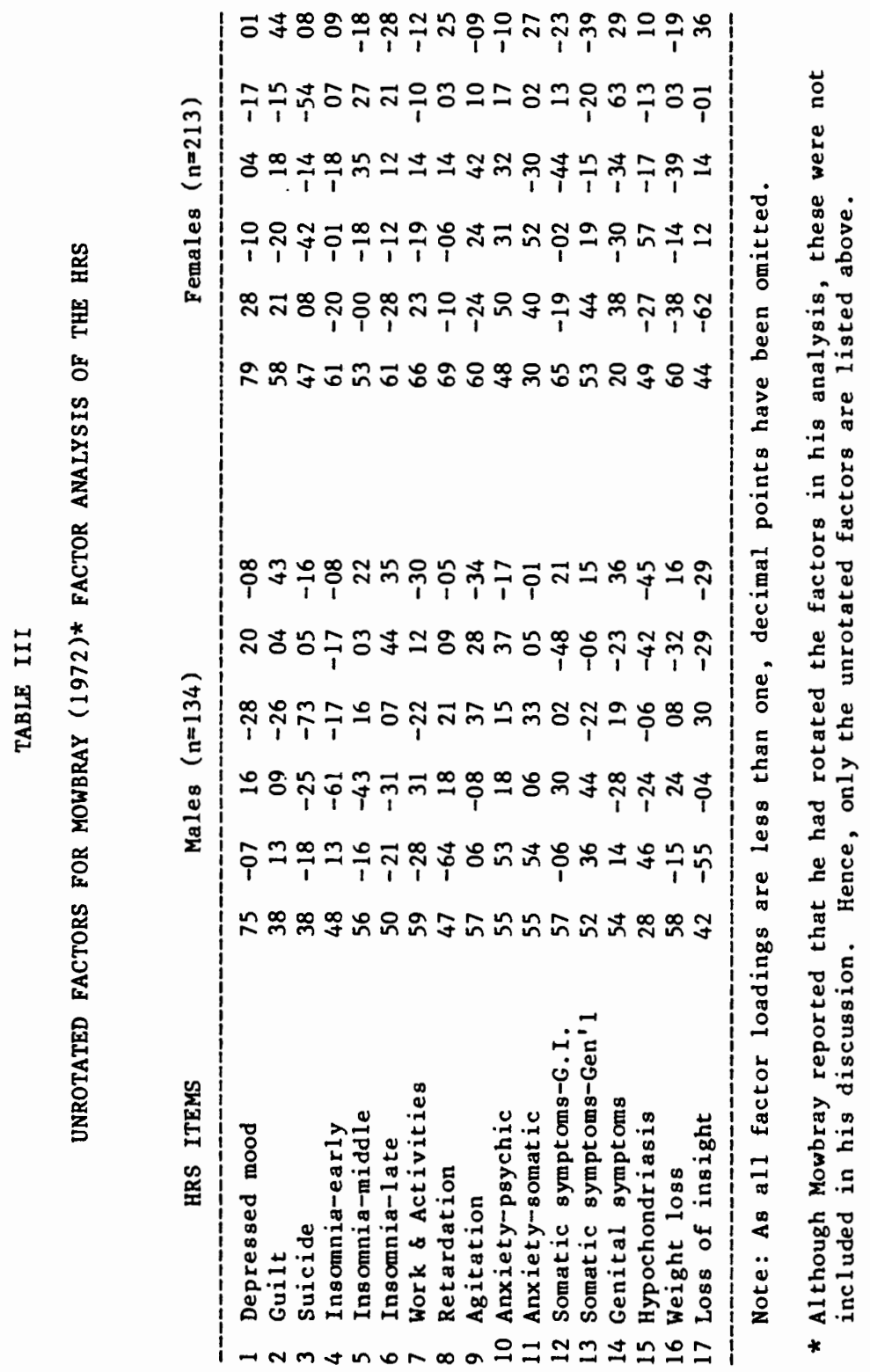


both the male and female samples, and correlated highly with total HRS score (.96 for males, and .93 for females).

While Mowbray must be credited for his efforts to adjust for many of the deficiencies in previous factor analytic studies, utilizing fairly large samples and including a wide range of severity, his inclusion of a control group of 18 patients seen in general practice may have served to inflate the values of the correlation coefficients by exaggerating the range of total HRS scores which may not be truly representative of a depressed population. Specifically, the mean HRS score of this group of non-depressed individuals was 4.1 $(S D=1.04)$; according to Mowbray, a score less than ten "would be consistent with normal mood". Two final drawbacks that 1 imit the generalizabilty of these findings address Mowbray's failure to include adequate demographic data (i.e., information on diagnosis, and a breakdown of patients by treatment setting), and his failure to report the rotated factors.

Summary of Factor Analytic Research of the HRS

Since its initial development in 1960, the HRS has been the object of several factor analytic investigations, each of which attempted to assess the instrument for factorial invariance. Overall, two factors have emerged with some consistency. The first factor, a bipolar one, contrasts Retardation with Agitation, Anxiety-somatic, and Anxiety-psychic. The second factor to emerge consisted of a "core" of three items which appeared in nearly every study: Depressed mood (\#1), Retardation (\#8), and Genital symptoms (\#14). In the 
Hamilton (1967) investigation, these items emerged along with most of the other HRS items on a factor which Hamilton described as a "General factor of depressive illness" measuring severity. However, other than the three items described above, discrepancies existed between the Hamilton (1967) and Weckowicz et al. (1971) factor on eight additional items, casting further uncertainty on the interpretation of the Weckowicz et al. factor.

The preceeding discussion included many sources of variation in methodology between the four studies that may have contributed to the lack of consensus. These differences can be summarized as follows. First, in two of the studies (Hamilton, 1960; and Weckowicz, et a1., 1971), samples of 52 or fewer patients were employed---a "very poor" by Comrey's criteria, and considerably below the 170 required by Nunnally's recommendation of ten subjects per item. By restricting the range of scores, inadequate sample size may serve to distort the correlation coefficients and consequently, the resultant factor analysis.

Second, striking differences exist between the samples of the four studies described above. In the 1960 study Hamilton used British male inpatients, while in the 1967 investigation he used these same inpatients, plus 39 additional inpatients, hospital outpatients and patients seen in an acute admission ward. Weckowicz et al. (1971) obtained their ratings from Canadian males treated in a psychiatric unit of a general hospital, while Mowbray (1972) included hospital inpatients, day patients, outpatients, and even a group of 
non-depressed patients seen in general practice. While variations in treatment setting have been shown to influence the clinical dimensions of depression (Paykel, et al., 1970), it has also been demonstrated that the inclusion of unrelated syndromes may distort the resultant factor analysis (Hunt, et al., 1967).

Third, variations in the mathematical procedures required for any factor analysis may influence the kinds of dimensions that emerge. In two of the studies, Hamilton (1967) and Weckowicz et al. (1971), Varimax rotation was employed; Mowbray (1972) reported unrotated factors only; while Hamilton (1960) used an orthogonal hand-rotated matrix.

In an effort to correct the deficiencies cited in previous investigations, the present study followed a two-tier approach: First, to examine the replicability of dimensions obtained from the HRS, separate factor analyses were performed on two groups formed by a random division of the total sample of depressed outpatients who were being treated in a private psychiatric clinic. The sample size of 185 patients per group fulfilled the ten-subjects-per-variable rule of thumb suggested by Nunnally (1968), and fell just 15 patients short, (7 1/2\%), of a "fair" rating according to Comrey's criteria (1973). Furthermore, the combined sample size of 365 patients represents one of the largest samples to date in factor analytic research using the HRS exclusively. While some patients had previously sought hospitalization for depressive symptomatology, the effects of treatment setting on the present factor analysis should have been 
minimized since all patients were seeking treatment from the same psychiatric clinic.

The second stage of the investigation entailed a factor analysis of the entire sample, after examining the factor structure yielded by the two randomly formed groups. In addition, factor scores were computed for each subject and correlated with total score--a procedure also performed by Hamilton (1967) and Mowbray (1972). Presented in Table IV is a comparison of the present investigation to the four studies mentioned previously. Each study was evaluated in terms of meeting certain criteria, such as inclusion of demographic information, breakdown of patients by treatment setting, sufficiency of sample size, and type of factor analytic methods employed. In general, the present study met all of the criteria, while the other studies were deficient in several areas.

\section{Hypotheses}

While it was postulated with some certainty that a bipolar factor would emerge contrasting Retardation at one end with Agitation, Anxiety-somatic, and Anxiety-psychic at the other, it was also hypothesized that a general factor of severity would emerge, with substantial loadings on many of the HRS items. However, this last hypothesis was proffered with less confidence, since one of the previous investigators (e.g. Weckowicz, et al., 1971) failed to confirm this factor in their analyses. It was also postulated that the factor structure of the HRS would be replicated across the two random samples, at least for those factors with the largest sums of 


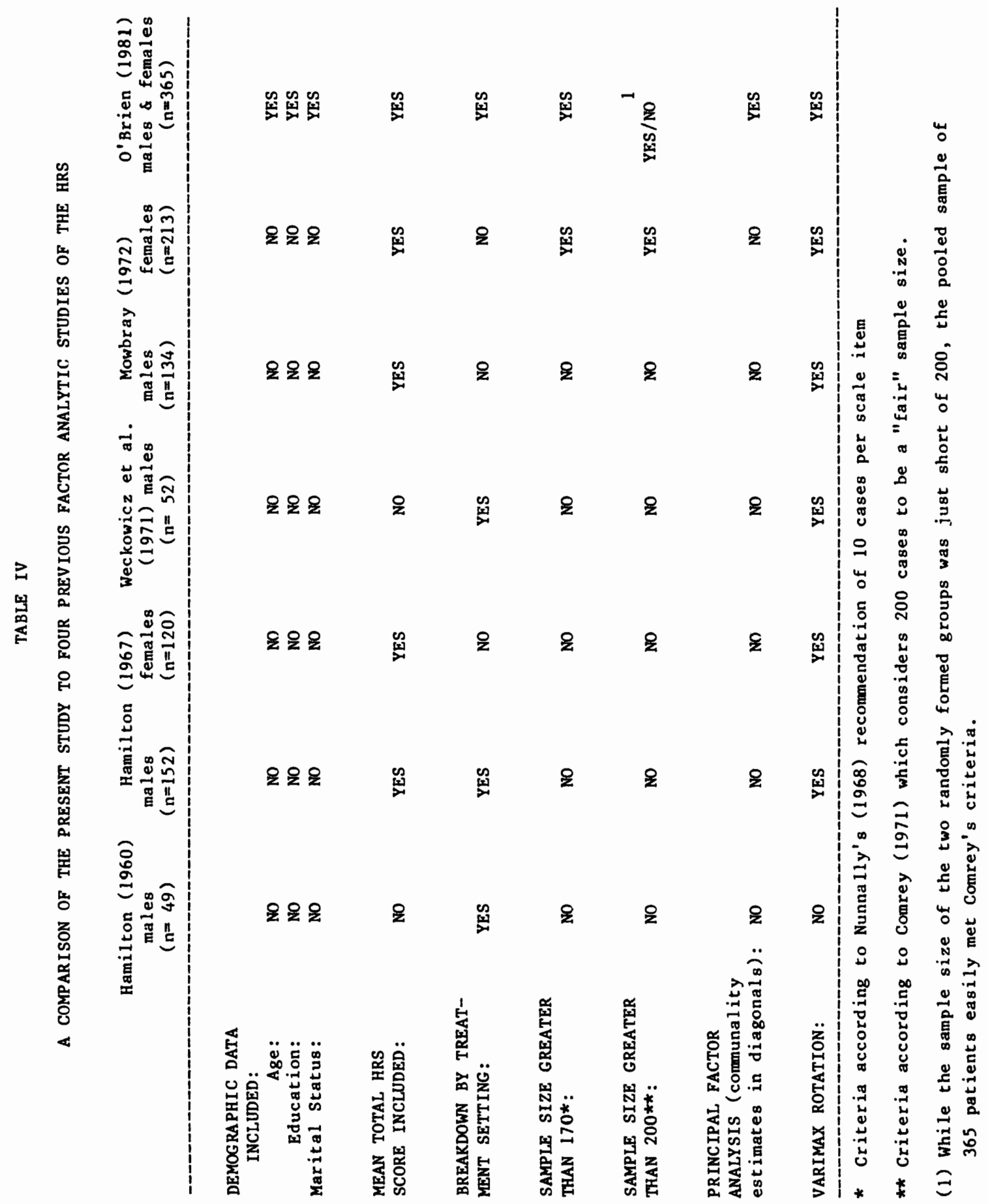


squares ( $S S Q$ ), and that the percent common (and percent total)

variance accounted for by each random sample would bé of appoximately the same magnitude. 
CHAPTER III

\section{METHOD}

\section{Subjects}

Subjects were patients with a chief complaint of depressive symptomatology, who sought treatment from a private psychiatric clinic staffed by a psychiatrist, clinical psychologist, and registered nurse. All patients were diagnosed as suffering from moderate to severe depressive disorders of the unipolar type. As part of an independent investigation.involving antidepressant medication, all subjects were given extensive psychological and physiological tests. Pre-existing psychiatric conditions in which depression was not a primary symptom, current alcoholism, severe psychomotor retardation, and family history of mania, were all criteria for exclusion from the study. Specific entrance requirements included: (a) a minimum score of eight on the Raskin Depression Scale (a three-item scale yielding a maximum score of 15); (b) endorsement of at least five items on the Feighner Depression Checklist (ten possible): and (c) a score on the Covi Anxiety Scale (a three-item scale yielding a maximum score of 15) no greater than the score obtained on the Raskin Depression Scale.

\section{Procedure}

All subjects were interviewed by either a clinical psychologist, psychiatrist, or registered nurse, one week prior to their admission to the antidepressant medication study from which ratings on the standard 17-items HRS were obtained. As described earlier, the HRS consists of 
nine items on a 0-2 continuum, and eight items on a 0-4 continuum. Initially, Hamilton (1960) recommended that the sum of two clinicians' ratings be used to compute the total score for a particular patient. Later, when reliability coefficients between .87 and .93 were reported in the literature, many investigators began using the doubled scores of just one clinician. Currently, the undoubled scores of a single investigator are employed by many researchers, a strategy followed in this study. Prior to the study, the three investigators practiced administering the rating scale via videotape, until their ratings of overall score agreed to within two points of each other; according to Hamilton (1967), agreement to within four points between two raters on the HRS total score had been considered adequate.

Data Analys is

Three-hundred-sixty-five subjects, 256 females and 109 males, were randomly assigned to one of two groups: Group 1 comprised 128 females and 55 males; Group 2 contained 128 females and 54 males. In both samples the female-to-male ratio was approximately 2.5 to 1 . Table $V$ provides a breakdown by sex, age, education, marital status, race, and HRS total score for each group and indicates the high degree of similarity between the two samples. Comparisons between the two groups on each of the demographic variables were performed by $\underline{t}$ test (in the cases of age, education, and HRS total score), or Chi-square (in the cases of marital status and race), which yielded no differences significant at $p<.05$. With the exception of a significant difference $(p<.01)$ in education between the sexes in the 


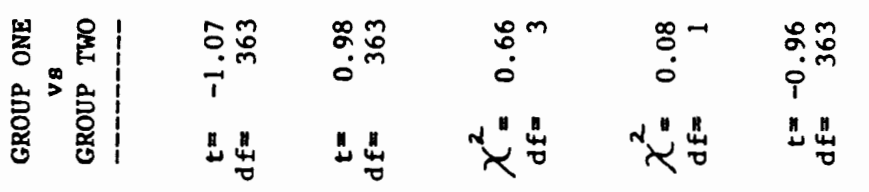

옹

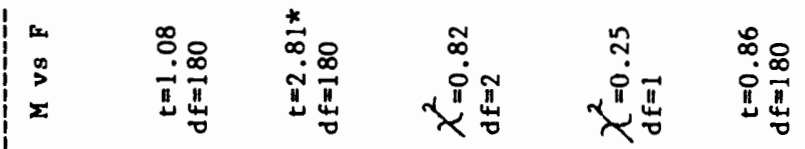

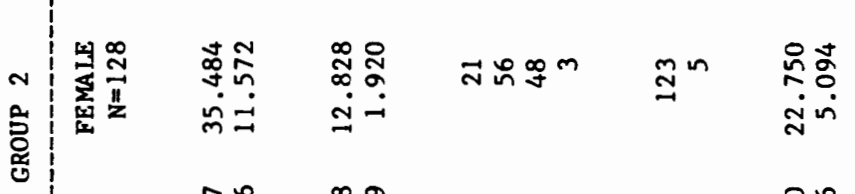

땔

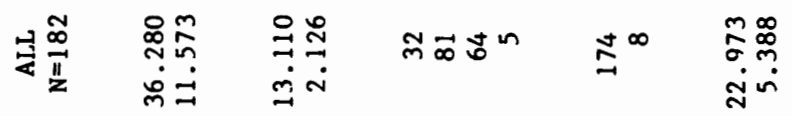

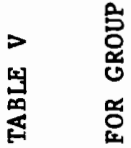

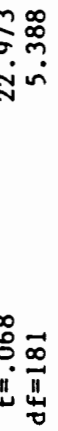

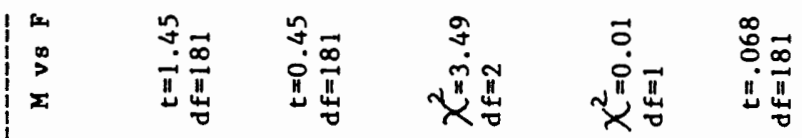

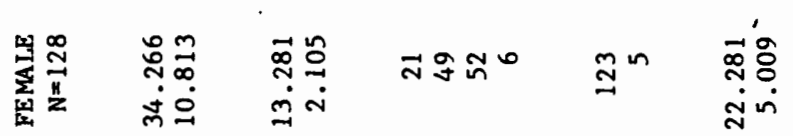

密

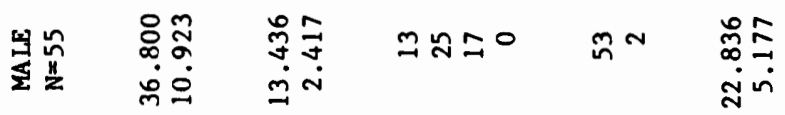

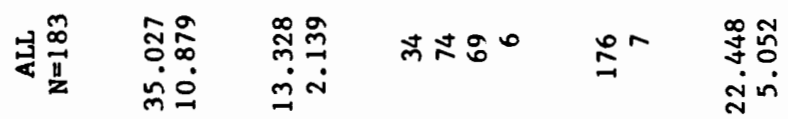

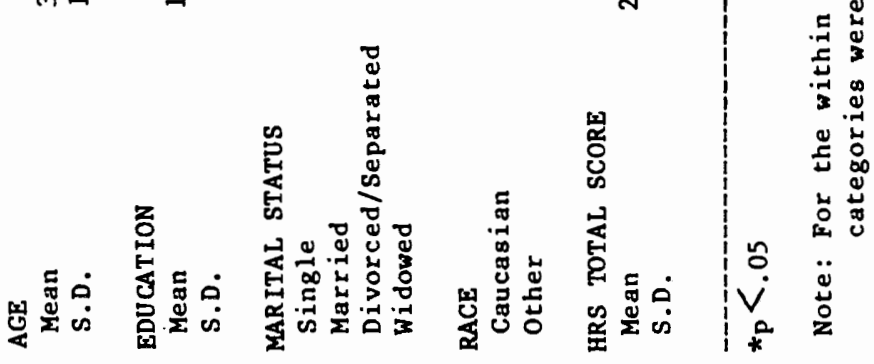


Group 2 sample, comparisons betwen males and females within groups produced no significant differences at $p<.05$. As illustrated in Figure 1, the distributions of HRS total scores for both groups were approximately normal, bell-shaped curves.

The 17 HRS items were factor analyzed separately for Group 1 and Group 2 by means of the Statistical Package for the Social Sciences (SPSS). The principal factor analysis procedure utilized Pearson product-moment correlation coefficients to construct the intercorrelation matrix, and placed communality estimates in the diagonals. The sum of the squared multiple correlations between each item and all remaining items were used as communality estimates. Prior to the principal factor analysis solution, a principal components analysis (which placed one's in the diagonals) was performed to determine the number of factors to be retained for rotation. All the unrotated factors subject to rotation were required to have eigenvalues at least equal to 1.00 . The resulting unrotated factor matrix was then rotated by the Varimax procedure (Kaiser, 1958) which yields orthogonal (uncorrelated) factors.

After determining that the demographic composition and factorial structure for the two groups were comparable, the two samples were combined. Employing the same mathematical procedures that were used in the previous analyses, an intercorrelation matrix was constructed for the principal factor analysis with communality estimates placed in the main diagonal. According to the procedures employed in the first analyses, six unrotated factors were extracted, each having 

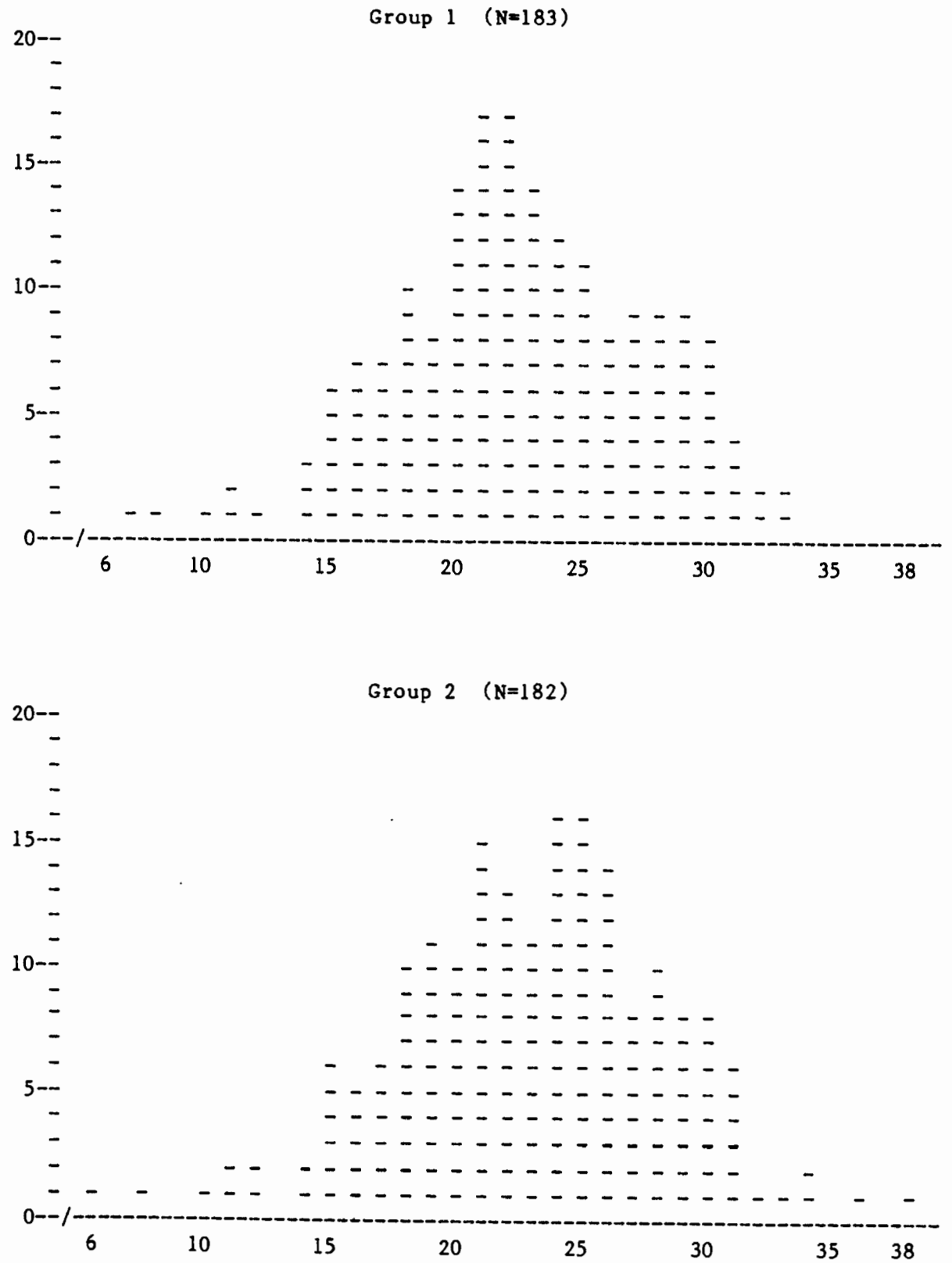

Figure 1. Distribution of HRS total scores for Group 1 and Group 2. 
eigenvalues greater than 1.00 . The resultant unrotated factor matrix was then rotated using the Varimax procedure to produce a matrix of factor loadings for six orthogonal factors. In addition, factor scores generated by the SPSS computer program utilizing the relative contributions from all the 17 items were computed for all subjects, and then correlated with total score as well as with each other. 


\section{CHAPTER IV}

\section{RESULTS}

Presented in Appendices A through $C$ are the intercorrelation matrices, unrotated factors, and rotated factors for Group 1 and Group 2. To avoid confusion, factors from the Group 1 analysis have been denoted by "1-1, 1-2, 1-3 ..." etc.; the Group 2 factors by "2-1, 2-2, 2-3 ..." etc.

Inspection of the unrotated factor matrices suggested that six factors presented the clearest structure for both groups. In the Group 2 analysis, eight unrotated factors emerged with eigenvalues greater than one; however, because the last two factors had eigenvalues very close to one, and since the purpose of the study was to compare the group's analyses using the same number of factors, only the first six were retained for further rotation. In each group the set of six rotated factors accounted for approximately $40 \%$ of the total variability of the 17 HRS items.

Overa11, the intercorrelations between items were low: (a) in Group 1 no intercorrelations exceeded an absolute magnitude of .50 ; four were between .40 and .49 ; one was between .30 and $.39 ; 18$ were between .20 and .29; the remaining 113 intercorrelations were less than or equal to .19. (b) Similarly, in Group 2 no intercorrelations exceeded an absolute magnitude of .50 ; three were between .40 and .49 ; six were between .30 and $.39 ; 14$ were between .20 and .29 ; the remaining 113 intercorrelations were less than or equal to .19 . 
Within each sample, items with factor loadings greater than or equal to .30 were considered to define a factor. For Group 1, 15 of the 17 HRS items emerged on at least one factor with loadings greater than .30 or less than -.30; similarly, for Group 2, 13 of the 17 HRS items emerged on at least one factor with loadings greater than .30 or less than -.30. The factor descriptions, HRS item stems, and factor loadings are presented in Tables VI and VII for Groups 1 and 2, respectively.

Factor Descriptions for Group 1

Referring to Table VI, the first factor to emerge appeared to involve a gastrointestinal disturbance and contained two items with loadings above .30 . The first item dealt with weight loss as reported by the patient, or as in some cases, weight loss as measured by the clinician. The second item described a reliance on laxatives or other bowel medications, and a loss of appetite.

Probably related to somatic concerns factor 1-2 contained five items with loadings above .30 , the first two of which involved such complaints as dry mouth, palpitations, sighing, sweating, urinary frequency, heaviness in limbs, and fatigability. The three remaining items assessed the amount of subjective tension and irritability, preoccupation with health, and loss of interest in work or one's usual activities; all had loadings of about .40 or less.

The third factor to emerge, 1-3, with five loadings above .30, appeared to characterize a dimension of dysphoria. Three items which had the largest loadings concerned feelings of hopelessness and 
TABLE VI

FACTOR DESCRIPTIONS, HRS ITEMS, AND FACTOR LOADINGS

FOR GROUP $1 \quad(N=183)$

\section{\#1-1 GASTROINTESTNAL DISTURBANCE}

16. Loss of weight: probable or definite loss according to patient; less than one pound of loss, greater than one pound, or greater than two pounds of loss in a week as by clinician.

12. Somatic symptoms-gastrointestinal: 10ss of appetite, heavy feeling in abdomen, difficulty in eating without encouragement, requests or requires laxatives for bowels .

\section{\#1-2 SOMATIC CONCERNS}

11. Anxiety-somatic: physiological concomitants such as dry mouth, indigestion, palpitations, headaches, hyperventilation, urinary frequency, sweating.

13. Somatic symptoms-general: heaviness in 1 imbs, muscle aches, loss of energy, and fatigability.

10. Anxiety-psychic: subjective tension and irritability, worrying, apprehensive attitude apparent in face or speech, fears expressed spontaneously.

15. Hypochondriasis: bodily self-absorption, preoccupation with health, frequent complaints or requests for help.

7. Work \& Activities: feelings of incapacity or fatigue, loss of interest in usual activities, decreased productivity, cessation of work or employment. 
TABLE VI (continued)

\section{*1-3 DYSPHORIA}

1. Depressed mood: feelings of sadness, hopelessness, helplessness, and worthlessness.

3. Suicide: feelings that life is not worth living, want 8 to die, suicidal ideas or gestures, suicidal attempt.

7. Work \& Activities: feelings of incapacity or fatigue, loss of interest in usual activities, decreased productivity, cessation of work.

2. Feelings of guilt: self-reproach, ideas of guilt, delusions of guilt, hallucinations (accusatory).

10. Anxiety-psychic: subjective tension and irritability, worrying, apprehensive attitude apparent in face or speech, fears expressed spontaniously.

\section{$\# 1-4$ SLEEP DISTURBANCE}

5. Insomnia-middle: complaints of being restless and disturbed during the night, waking during the night.

6. Insomnia-late: waking in early morning, but goes back to sleep; unable to go back to sleep once out of bed.

15. Hypochondriasis: bodily self-absorption, preoccupation with health, frequent complaints or requests for help.

\section{\#1-5 PATHOLOGICAL LEVEL OF ACTIVITY}

9. Agitation: "Playing with" hands, hair, etc.; handwringing, nail-biting, chewing of lips.

8. Retardation: slowness of thought and speech, impaired ability to concentrate, decreased motor activity.

\section{\#-6 DENIAL}

17. Loss of insight: denies being ill at all, acknowledges illness but attributes cause to bad food, climate, overwork, virus, need for rest, etc.

2. Feelings of guilt: self-reproach, ideas of guilt, delusions of guilt, hallucinations (accusatory). 
helplessness, that life is not worth living, and a loss of interest in one's work or usual activities. The last two items dealt with feelings of guilt and self-reproach, as well as with feelings of subjective tension and irritability.

Factor 1-4 contained three items loadings greater than or equal to .30 , and seemed to describe a sleep disturbance. The first two items, with moderate to high loadings, involved restlessness during the night, as well as early morning awakening and difficulty in falling back asleep once out of bed. The third and last item concerned a preoccupation with health and bodily self-absorption, correlating only .315 with this factor.

Factor 1-5, which emerged as a bipolar factor, appeared to define a pathological level of activity ranging from retardation to agitation. The first item, with a loading of .654 , dealt with such behaviors as "playing with" hands or hair, hand-wringing, nail-biting, and biting of lips. The second item, with a negative loading of -.576 , involved slowness of thought and speech, impaired ability to concentrate, and decreased motor activity.

Not clearly interpretable, factor 1-6 emerged as a bipolar dimension with two loadings, and tentatively labelled Denial. The first item dealt with insight into the cause of illness (acknowledges being depressed; denies being depressed; attributes depression to bad food, a virus, overwork, etc.) and loaded .591 with this factor. The second item, correlating just -.339 with this factor, described feelings of guilt and self-reproach. Of interest here is the finding 
that over $96 \%$ of the subjects in Group 1 obtained a score of zero on the Insight item (\#17) of the HRS---a finding that further casts suspicion on the stability of this factor.

Overall, five of the six factors that were identified seemed interpretable. Moreover, only three of the 17 HRS items (非, 非, 非10) appeared with loadings above .30 on two factors, while none appeared on more than two factors. Finally, two items--Insomnia-early (非) and Genital symptoms (非4), failed to appear on any factor in this analysis with loadings exceeding .30 .

Factor descriptions for Group 2

As illustrated in Table VII, the first factor of the Group 2 analysis contained four items with loadings greater than .30 and appeared to characterize a dysphoria. Similar to the third factor in the previous analyses, the items that emerged described feelings of hopelessness and helplessness, worthlessness, subjective feelings of tension and irritability, and a decreased interest in work or one's usual activities. An additional item with a rather low loading (.389) emerged for this factor, describing slowed thoughts and reduced motor activity; this item did not appear in the corresponding factor of the Group 1 analysis. Two items which appeared in the first sample's factor labelled dysphoria, concerning feelings of self-reproach, that life is not worth living, and suicidal ideas, failed to replicate on the similarly named factor in this analysis.

Factor 2-2, apparently describing a sleep disturbance, emerged with three loadings greater than .30 . Two of the items which also 
TABLE VII

FACTOR DESCRIPTIONS, HRS ITEM STEMS, AND FACTOR LOADINGS

FOR GROUP $2 \quad(\mathrm{~N}=182)$

\section{\#2-1 DYSPHORIA}

1. Depressed mood: feelings of sadness, hopelessness, helplessness, and worthlessness.

10. Anxiety-psychic: subjective tension and irritability, worrying, apprehensive attitude apparent in face or speech, fears expressed spontaneously.

7. Work \& Activities: feelings of incapacity or fatigue, loss of interest in usual activities, decreased productivity, cessation of work or employment.

8. Retardation: slowness of thought and speech, impaired ability to concentrate, decreased motor activity.

\section{\#2-2 SLEEP DISTURBANCE}

5. Insomnia-middle: complaints of being restless and disturbed during the night.

6. Insomnia-late: waking in early morning, but goes back to sleep; unable to go back to sleep once out of bed.

4. Insomnia-early: complaints of occasional difficulty falling asleep--i.e., more than one-half hour; complaints of nightly difficulty in falling asleep.

\section{\#2-3 GASTROINTESTINAL DISTURBANCE}

12. Somatic symptoms-gastrointestinal: loss of appetite, heavy feeling in abdomen, difficulty in eating without encouragement, request $\mathrm{B}$ or requires laxatives for bowels.

16. Loss of weight: probable or definite loss according to patient; less than one pound, greater than one pound, or greater than two pounds of weight loss in a week as measured by clinician. 
TABLE VII (continued)

\section{*2-4 PATHOLOGICAL LEVEL OF ACTIVITY}

9. Agitation: "Playing with" hands, hair, etc.; handwringing, nail-biting, and chewing of 1 ips.

8. Retardation: slowness of thought and speech, impaired ability to concentrate, decreased motor activity.

\section{\$2-5 SOMATIC CONCERNS-A}

15. Hypochondriasis: bodily self-absorption, preoccupation with health, frequent complaints or requests for help.

11. Anxiety-somatic: physiological concomitants such as dry mouth, indigestion, palpitations, headaches, hyperventilation, urinary frequency, sweating.

\section{\#2-6 SOMATIC CONCERNS-B}

13. Somatic symptoms-general: heaviness in limbs, muscle aches, loss of energy, and fatigability.

11. Anxiety-somatic: physiological concomitants such as dry mouth, indigestion, palpitations, headaches, hyperventilation, urinary frequency, sweating. 
appeared in the Group 1 analysis, concerned wakefullness during the night, and early morning awakening. The third item, which did not appear in the Group 1 analysis, assessed difficulty in falling asleep and correlated .384 with this factor. While an item which described a preoccupation with health exhibited a low correlation with a similarly named factor in the Group 1 analysis, this item did not correlate above .30 in the Group 2 factor.

The third factor, labelled gastrointestinal disturbance, appeared to correspond very closely to its Group 1 counterpart and contained two items with loadings exceeding .30 . The first item described a loss of appetite and reliance on laxatives and other types of bowel medications, while the second item dealt with weight loss as reported by the patient.

Nearly identical to the bipolar factor which emerged in the Group 1 analysis (1-5), the fourth factor of Group 2 similarly characterized a pathological level of activity ranging from retardation to agitation. With a high positive loading (.712), the first item described such behaviors as nail-biting, "playing with" hands and hair, biting of 1 ips, and hand-wringing. The second item emerged with a negative loading of moderately high magnitude (-.615) and involved slowness of thought and speech, impaired ability to concentrate, and decreased motor activity.

The last two factors, $2-5$ and $2-6$, were more tentative in nature than the factors previously discussed. The one item common to both factors, correlating . 311 with the fifth factor and .389 with the 
sixth, involved such complaints as headaches, sweating, palpitations, urinary frequency, and dry mouth. For this reason the two factors were labelled somatic concerns $A$ and somatic concerns $B$.

The second item of factor 2-5 described a preoccupation with health, bodily self-absorption, and frequent requests for help, while the second item of factor 2-6 dealt with loss of energy, fatigability, and muscle aches. Finally, a finding of interest is that all three of the items which accounted for factors 2-5 and 2-6 in this analysis emerged on a single factor $(1-2)$ in the Group 1 analysis.

In the factor analysis for Group 2 described above, two HRS items (\#8,\#11) appeared with loadings above .30 on two different factors. Finally, four items, Feelings of guilt (非), Suicide (非), Genital symptoms (\#14), and Loss of insight (\#17), failed to emerge with a loading of .30 or greater in the Group 2 analysis.

Comparisons of Group 1 and Group 2 Factor Structures

Overall, the analyses of the two samples displayed considerable agreement on four factors. As illustrated in Appendix $C$, the percent total variance accounted for by each analysis, 39.1 for Group 1 and 40.9 for Group 2, was of nearly the same magnitude. Furthermore, the percent common variance accounted for by each of the Group 1 factors was approximately equal to their Group 2 counterparts, deviating at most by $2.9 \%$.

Comparisons between the remaining two factors for each group required a more cautious approach since these subsequent factors seemed more tentative in nature. As described previously, factors 2-5 
and 2-6 of the second analysis appeared to be of similar composition to the second factor of the Group 1 analysis. That the items comprising these factors should cluster on one factor in one analysis but not in the other strengthens the impression that they may not be stable enough to warrant serious consideration at this time. The sixth factor of the first analysis, tentatively labelled Denial, contained one item (非, Feelings of guilt) with a rather low loading $(-.339)$ and one item (\#17, Loss of insight) in which $96 \%$ of the patients obtained a score of zero; it subsequently failed to replicate in the Group 2 analysis as well. Moreover, the Genital symptoms item (\#14) failed to emerge in both analyses on any factor with a loading exceeding an absolute magnitude of .30 .

In summary, the comparison of the analyses demonstrated replicability of four factors labelled Dysphoria, Sleep disturbance, Gastrointestinal disturbance, and Pathological level of activity. A fifth factor, best described as one involving Somatic concerns, also emerged in each of the two samples but with less stability than the four factors just discussed.

Factor Descriptions for Total Sample $(\mathrm{N}=365)$

The intercorrelation matrix, unrotated factors, and rotated factors are presented in Appendices D, E, and F respectively. Table VIII includes factor descriptions, HRS items, and factor loadings above .30 for the six factors which emerged in the principal factor analysis which placed the communality estimates of the variables in the diagonal of the intercorrelation (․) matrix. 
TABLE VIII

FACTOR DESCRIPTIONS, HRS ITEMS, AND FACTOR LOADINGS

FOR ENTIRE SAMPLE $(\mathrm{N}=365)$

\section{$\$ 1$ - SLEEP DISTURBANCE}

5. Insomnia-middle: complaints of being restless and disturbed during the night; waking during the night. $\quad 766$

6. Insomnia-late: waking in early morning but goes back to sleep; unable to go back to sleep once out of bed.

\section{\#2 - SOMATIC CONCERNS}

11. Anxiety-somatic: physiological concomitants such as dry mouth, indigestion, palpitations, headaches, hyperventilation, urinary frequency, sweating.

13. Somatic symptoms-general: heaviness in 1 imbs, muscle aches, loss of energy, and fatigability.

15. Hypochondriasis: bodily self-absorption, preoccupation with health, frequent complaints or requests for help.

10. Anxiety-psychic: subjective tension and irritability, worying, apprehensive attitude apparent in face or speech, fears expressed spontaneously.

\section{\#3 - GASTROINTESTINAL DISTURBANCE}

12. Somatic symptoms-gastrointestinal: 1088 of appetite, heavy feeling in abdomen, difficulty in eating without encouragement, requests or requires laxatives for bowels.

16. Loss of weight: probable or definite 1088 according to patient; less than one pound, greater than one pound, or greater than two pounds of weight 1088 as measured by clinician. 
TABLE VIII (continued)

\section{\#4 - DYSPHORIA}

1. Depressed mood: feel ings of sadness, hopelessness, helplessness, and worthlessness.

7. Work \& Activities: feelings of incapacity or fatigue, loss of interest in usual activities, decreased productivity, cessation of work or employment.

10. Anxiety-psychic: subjective tension and irritability, worrying, apprehensive attitude apparent in face or speech, fears expressed spontaneously.

3. Suicide: feelings that life is not worth living, wants to die, suicidal ideas or gestures, suicidal attempt.

2. Feelings of guilt: self-reproach, ideas of guilt, delusions of guilt, hallucinations (accusatory).

8. Retardation: slowness of thought and speech, impaired ability to concentrate, decreased motor activity.

\#5 - PATHOLOGICAL LEVEL OF ACTIVITY

9. Agitation: "Playing with" hands, hair, etc., handwringing, nail-biting, and chewing of 1 ips.

8. Retardation: slowness of thought and speech, impaired ability to concentrate, decreased motor activity.

\section{\#6 - (UNINTERPRETED FACTOR)}

15. Hypochondriasis: bodily self-absorption, preoccupation with health, frequent complaints or requests for help.

17. Loss of insight: denies being ill at all, acknowledges illness but attributes cause to bad food, climate, overwork, virus, need for rest, etc. 
The factor structure of the entire sample, as expected, reflected those factors that were replicated across the Group 1 and Group 2 analyses outlined above. Accounting for $35.7 \%$ of the total variabillity of the 17 HRS items, five interpretable factors emerged, along with a sixth factor which was left uninterpreted and unlabelled because it was considered too tentative to warrant further discussion. Of interest, those items that failed to replicate across similar factors in the two previous analyses tended to have loadings above .30 but less than .40 in this analysis. A conservative approach then, would consider only those variables with loadings greater than .40 as important facets of a given dimension.

Factor Scores on the HRS. As part of the principal factor analysis solution, factor scores were computed for each case on each of the six factors utilizing the contributions from all 17 HRS items. These scores were then correlated with HRS total score to examine the degree of association between each factor and severity of depressive symptomatology. These results have been incorporated in the following discussion.

Characterizing a sleep disturbance, the first factor to emerge correlated .476 with total score and contained two items with moderately high loadings (i.e., greater than .60). These items assessed complaints of restlessness during the night, early morning awakening, and inability to resume sleep once out of bed.

The second factor, labelled somatic concerns, emerged with two moderately high loadings and two relatively low loadings (i.e., less 
than .40 but greater than .30$)$. The first two items concerned such symptoms as dry mouth, urinary frequency, sweating and palpitations, as well as heaviness in limbs, muscle-aches, and loss of energy. The latter two items involved bodily self-absorption, preoccupation with health, and subjective tension and irritability. This factor correlated .500 with total HRS score.

The third factor emerged with two moderate to high loadings greater than .60 on variables which described loss of appetite, heavy feelings in the abdomen, reliance on laxatives, and loss of weight. Labelled gastrointestinal disturbance, this factor correlated .461 with total score.

Correlating .674 with total score, the fourth factor contained six loadings greater than .30 and was labelled dysphoria. Three items with loadings greater than .40 dealt with feelings of sadness, hopelessness and helplessness, feelings of incapacity or fatigue, loss of interest in usual activities, subjective tension and irritability. Three items with relatively low loadings, i.e., less than .40 , concerned feelings that life is not worth living, ideas of guilt and self-reproach, slowing of thought and speech, as well as decreased motor activity.

Factor 5, labelled pathological level of activity, emerged as a biploar factor with one positive loadings above .60 and one negative loading less than -.59 . The first item described behaviors characteristic of agitation such as "playing with" hands or hair, chewing lips, and nail-biting; the second item detected behaviors 
typical of psychomotor retardation---behaviors such as reduced motor activity, as well as slowness of thought and speech, and impaired concentration. While this factor also significantly correlated with HRS total score $(p<.001)$, the correlation coefficient of .149 was of very low magnitude.

The last factor, left unnamed, correlated .117 with total score and contained two items with relatively low loadings. The first item correlated .377 with this factor and concerned a preoccupation with health and bodily self-absorption. The second item emerged with a loading of .347 and dealt with loss of insight as to the cause of illness. Failing to appear in either the Group 1 or Group 2 analyses, this factor seemed too unstable to warrant further description. Moreover, it accounted for only $6.6 \%$ of the common variance for this analysis---less than half the variance accounted for by the next lowest factor.

In summary, four factors were replicated, albeit with minor variations, across two separate, but highly similar samples. A fifth factor was also suggested in that the same cluster of items which appeared on one factor in the first group's analysis loaded onto two separate factors in the Group 2 analysis.

When the two samples were combined, the resultant factor structure remained basically unchanged, except that the fifth factor, somatic concerns, clearly emerged as an identifiable dimension.

While all six factors correlated significantly with HRS total score ( $r x y \geqslant .117, N=365, p<.05$ ), four of the factors had correlation 
coefficients that exceeded .450: (a) dysphoria (.674); (b) somatic concerns (.500); (c) sleep disturbance (.476); and (d)

gastrointestinal disturbance (.461). Finally, when the factor scores themselves were correlated with each other as a test for orthogonality, two factors---dysphoria and gastrointestinal disturbance---exhibited a significant degree of association $(\mathrm{p}<.05)$; however, the correlation coefficient of rxy=.120, was of a very low magnitude. 
CHAPTER V

\section{DISCUSSION}

The Hamilton Rating Scale for depression (HRS) was developed in response to a growing need to measure the severity of a depressive episode, and has been found to be particularly useful in assessing the effects of antidepressant medication over the course of a depressive illness (Dykstra, 1969; Knesevich, et al., 1977; Rose, et al., 1965). An observer-rated scale, the HRS circumvented many of the difficulties inherent to self-report inventories such as response bias due to social desirability, and also demonstrated good inter-rater reliablity. After its initial presentation by Max Hamilton in 1960, attention turned towards the underlying structure of the HRS and towards the components contributing to the severity of depression.

Factor structure of the HRS

In the present study five readily identifiable factors emerged which appeared considerably less complex then the factors reported in the earlier investigations of Hamilton (1960; 1967), Mowbray (1972), and Weckowicz et a1. (1971). Two of the factors that appeared in this study, labelled dysphoria and pathological level of activity, appeared similar to dimensions described in previous investigations. However, as suggested above, fewer items emerged with loadings exceeding the .30 cut-off point for these two factors in the current study than in past research.

Labelled dysphoria in the present analysis, this factor shared 
many loadings in common with the factor Hamilton identified as a "General factor of depressive illness measuring severity". The shared items concerned feelings of helplessness and hopelessness (非-Depressed mood), guilt and self-reproach (非 Feelings of guilt), that $\mathrm{life}$ is not worth living (非-Suicide), and slowness of thought and speech (非-Retardation). However, additional items emerged on Hamilton's "General factor"---items describing such symptoms as loss of sexual response or menstrual disturbance (非14 Loss of libido) as well as diminished insight into the cause of illness (非17-Loss of insight), which failed to appear on the "dysphoria" factor of the present study.

Initially, Hamilton (1960) identified and labelled a factor he thought characterized a "Retarded Depression". However, later in the 1967 study, he modified his interpretation of this factor and called it a "General factor of depressive illness" measuring severity, noting that it correlated .93 with total HRS score. Hamilton further justified this choice of a label in reporting that the correlations between subsequent factors and total HRS score were less than . 30 , and "down to negligible levels".

In the present investigation, this factor was thought to be more concerned with a lowering of mood, rather than with general severity and was consequently labelled dysphoria. Two findings strengthen this impression: First, this factor correlated just .67 with total HRS score in the present study (compared to .93 obtained in Hamilton's 1967 study), accounting for only $45 \%$ of the variance in total score. 
Second, three other factors in this study, labelled somatic concerns, sleep disturbance, and gastrointestinal disturbance, correlated substantially with total HRS score, with coefficients ranging from .461 to .500 .

It has been noted by Hamilton (1967) that a restriction in the range of total scores could serve to suppress the emergence of a general factor of severity. While it is possible that the outpatient sample used in the present study represented a restricted range of severity in that hospitalized depressed patients were excluded, this explanation fails to account for the moderate correlations obtained between the other factors in this investigation.and total HRS score; other than the high correlation obtained between Hamilton's general factor and total score, all subsequent factors in his analysis failed to correlate more than .30 with total score.

A second factor of the present study, labelled pathological level of activity, appeared similar to a factor which emerged in both Hamilton investigations $(1960 ; 1967)$, as well as in the Weckowicz et a1. (1971) study. Two items in the present analysis loaded on this bipolar factor, which contrasted the Agitation item (非) at one end with the Retardation item (非) at the other. As in the present study, in which a low correlation of .149 was obtained between this factor and total HRS score, the similar bipolar factor which Hamilton named "Retarded vs Agitated" depression also exhibited a low association with total score $(\mathrm{rxy}=.30)$. 
Unlike previous analyses in which agitation also clustered with psychic- and somatic-anxiety on this factor, these items did not correlate well with each other or with the Agitation item in the present analysis. Consequently, it was proposed that this dimension better characterized a level of activity deviating from normal, rather than as a "Retarded vs Agitated" depression factor as suggested by Hamilton (1967).

Furthermore, the use of the label "Retarded vs Agitated" depression as used by Hamilton presents a somewhat misleadings view concerning the meaning attributed to factors. An orthogonal solution, such as the performed in the present study, the 1960 and 1967 studies of Hamilton, and in the 1971 study of Weckowicz and his associates, produces dimensions which are uncorrelated; this means that for a particular case, a score on one factor can vary independently of the score on any other given factor. In contrast, diagnostic labels theoretically represent categories which are mutually exclusive---e.g., a person could either by diagnosed as suffering from a "neurotic depression" or "psychotic depression" but not both. For this reason, labels which suggest diagnostic classifications or entities should be avoided, unless validated in subsequent analyses. In summary, the results of the present study suggest that five underlying dimensions account for the variations in severity as measured by HRS total score, four of which correlated between .461 and .674 with total score. These dimensions seem to describe a state of dysphoria and feelings of worthlessness, somatic concerns and 
preoccupation with health, disrupted sleep patterns, as well as disturbed eating habits and gastrointestinal distress. A fifth dimension, describing a pathological level of activity, correlated little with HRS total score and seemed to define a qualitative aspect of a depressive episode rather than directly contributing to overall severity per se. In a similar factor identified by Hamilton (1967), it was observed that this dimension may be correlated with improvement on antidepressant medication. While this hypothesis was not explored in the present investigation, it remains a fertile area for further research with this instrument.

While the results of the present investigation implicate several factors or clusters of symptoms as important variables in a depressive illness, they in no way suggest causality. However, an examination of how these dimensions change over the course of a depressive episode may yield important clues as to etiology, prognosis, and the underlying mechanisms which affect the quality and severity of sympt omatology.

Methodological Issues

One focus of the present study concerned the replicability of factors obtained from two, distinct but highly similar groups. While four factors appeared to replicate well across the two samples in the first part of the investigation, minor differences between these dimensions nonetheless occurred. While Hamilton noted that differences in factor structure between two samples could exist due to chance variations in the population, it has also been recognized that 
the stability of factor loadings can be affected by the diagonal values used as communality estimates (Bechtoldt, 1961). In principal components analysis (the method employed by Hamilton, Mowbray, and Weckowicz et a1.) the diagonal values are assumed to be equal to one (unity); but in principal factor analysis, the method employed in the present study, squared multiple correlations (SMC's) are used as communality estimates which not only differ from unity, but may vary from sample to sample as we11. Thus, differences between highly similar groups serve to: (1) caution against over-interpretation of single-study factor analytic results, especially when sample size is smal1; (2) function as a rough index of the variability to be expected when comparing the factor results from different investigators; and (3) underscore the need to consider only those items which repeatedly emerge on similar factors across different studies as being representative of that dimension---items with low loadings or which sometimes appear on a given factor, and other times do not, should be viewed skeptically and subjected to further examination.

The large sample size of the present study may have contributed to the purer, less complex factor structure that evolved, since according to Comrey (1973) correlation coefficients become more stable with increasing sample size. However, since this investigation did not include patients currently hospitalized for depression, this may have decreased the potential range of HRS total scores, thereby reducing the magnitude of the intercorrelations. A decrease in the 
intercorrelations between variables could result in fewer variables clustering together, and consequently, in less complex factors.

When the intercorrelation matrix for the entire sample $(N=365)$ of the present study was compared to the intercorrelation matrices obtained by Mowbray (1972) and Hamilton (1960; 1967) marked differences emerged in the overall magnitude of the intercorrelations: In the present analysis, $15 \%$ of the intercorrelations exceeded .19 . However, in Hamilton's investigations the number of intercorrelations exceeding .19 ranged from $30 \%$ to $35 \%$ while between $52 \%$ and $65 \%$ of the intercorrelations exceeded .19 in Mowbray's study. Weckowicz et al. (1971) did not report the intercorrelation matrix in the original article, but rather reported it through an auxilliary publication service to reduce printing costs. However, at the time of the present study, this material was not available from the publication company, and consequently was not included in the above comparisons.

As the intercorrelations between variables increases, the greater the likelihood that a general factor will emerge with substantial loadings on all or most of the items. Subsequent factors will tend to contain more moderate-to-low loadings---i.e., describing potentially ambiguous or complex dimensions.

One explanation that may account for the greater intercorrelations obtained by Hamilton compared to those of the present study involves Hamilton's practice of utilizing "half-points" in scoring the HRS. While he asserted that with familiarity a rater could distinguish half-point gradations, (which in effect expands the 
three point items to five points, the five point items to 9 points), many researchers, such as the ones which participated in this study, do not follow this convention. By increasing the range per item, Hamilton may have increased the resulting intercorrelations.

On the other hand, the large intercorrelations reported by Mowbray (1972) may be attributable to his inclusion of patients exhibiting "minimal depressive symptomatology", as well as normal controls seen in general practice; both procedures could have served to inflate the range of severity, and hence the correlation coefficients. Furthermore, this range may not be truly representative of a depressed population; by Mowbray's own account the mean HRS score of 4.1 obtained by his control group was "consistent with normal mood". Moreover, Hamilton himself recommended that the HRS is to be used only with patients diagnosed as suffering from depression. Prior to performing a factor analysis careful attention should be focused on the distribution of scores for each item as a check for normality, and ideally on the scatterplots of the intercorrelations between each pair of variables as a check for linearity. While deviation from normality on some items is to be expected---especially when dealing with individual items of a scale, severe deviations should serve as a warning, particularly when interpreting factors which contain the questionable items. Consider for example, the HRS item $\equiv_{17}$ (Loss of insight) on which $96 \%$ of the patients in the present study obtained a score of zero. Obviously, this item would not be considered a good "marker" variable with which to describe a factor, 
even if it happened to emerge with a (spuriously) high loading. Without this type of examination, individual items may be erroneously given too much, or too little consideration when the factor structure is being interpreted. None of the studies cited above (Hamilton, 1960 and 1967; Mowbray, 1972; Weckowicz et a1., 1971) reported that this type of analysis had been performed, thus precluding a direct comparison with the results of other similar studies, as well as with those of the present investigation.

Limitations of the Present Study

To insure that an adequate sample size had been achieved, males and females were pooled in all analyses. However, the clinical features of depressive illness may not be the same for males as it is for females. Hamilton (1967) reported sex differences on the incidence of depression (women were higher than men), and also on the mean age of onset for patients admitted to the hospital (females were younger than their male counterparts). Furthermore, Hamilton (1967) found seven HRS items in which males differed significantly from females. These differences were confirmed for three of the items in the present investigation, where males rated higher on items 1 7 (Work \& Activities), 非 (Retardation), and 非15 (Hypochondriasis).

Conclusions

In summary, the results of the present investigation indicate that, given similar groups and adequate sample size, the HRS can exhibit factorial invariance--i.e., that factors can be replicated 
across two groups. While four interpretable factors emerged across the two randomly formed groups, a fifth factor emerged when a factor analysis of the entire sample was performed. These five factors, labelled sleep disturbance, somatic concerns, gastrointestinal disturbance, dysphoria, and pathological level of activity, plus a sixth uninterpreted factor, accounted for approximately 36 percent of the variablility of the HRS items. Future research should be directed towards a further evaluation of the factors of the HRS (through the use of factor scores), and their ability to differentiate various groups of patients, as well as in predicting outcome following treatment. Furthermore, additional factor analytic research should attempt to include ratings from a variety of sources, which include the HRS and other psychological tests, as well as physiological data in order to more fully explore the dimensions underlying severity of symptoms in depression. 


\section{REFERENCES}

Ahmavaara, Y. Transformation analysis of factorial data. Annales Academie Scientarum Fennicae, 1954, 88, 2.

Anastasi, A. Psychological Testing (Third Edition). New York: MacMillan Publishing Company, 1968.

Bailey, P. \& Coppen, A. Comparison between the Hamilton Rating Scale and the Beck Depression Inventory in the measurement of depression. British Journal of Psychiatry, 1976, 128, 486-489.

Bech, P., Gram, L.F., Dein, E., Jacobsen, 0., Vitger, J., \& Bolwig, T.G. Quantitative rating of depressive states. Acta Psychiatria Scandinavica, 1975, 51, 161-170.

Bechtoldt, H. An empirical study of the factor analytic stability hypothesis. Psychometrika, 1961, 26, 405-432.

Beck, A.T., Ward, C.H., Mendelson, M., \& Erbaugh, J. An inventory for measuring depression. Archives of General Psychiatry, 1961, 4, 561-571.

Breaking the Chains of Depression. The Encyclopedia of Common Diseases, December, $1976,583-\overline{587}$.

Carrol1, B.J., Fielding, J.M., \& Blashki, T.G. Depression Rating Scales. Archives of General Psychiatry, 1973, 28, 361-366.

Cattell, R.B. Factor analysis: An introduction to essentials. I. The purpose and underlying models. Biometrics, 1965, 21, 190-215.

Cattell, R.B. Factor analysis: An introduction to essentials. II. The role of factor analysis in research. Biometrics, 1965, 21, 405-435.

Coleman, J.C. Abnormal psychology and modern life (5th edition). Glenview, Illinois: Scott, Foresman, and Company, 1976.

Comrey, A. A first course in factor analysis. New York: Academic Press, 1973.

Creasy, M.A. Some criticism of factor analysis with suggestions for alternative methods. Journal of Mental Science, 1959, 105, 755-761. 
REFERENCES (continued)

Davies, B., Burrows, G., \& Poynton, C. A comparative study of four depression rating scales. Australian and New Zealand Journal of Psychiatry, 1975, $9,21-24$.

Derogatis, L.R., Lipman, R.S., Covi, L., \& Rickels, K. Neurotic symptom dimensions. Archives of General Psychiatry, 1971, 24, 454-464.

Dykstra, P. Some methods for measuring changes in the behavior of depressive patients. Psychiatria, Neurologia, and Neurochirurgia, $1969, \overline{72}, 219-224$.

Guertin, W.H., \& Bailey, J.P. Introduction to modern factor analysis. Ann Arbor: Edwards, 1970.

Hamilton, M. A rating scale for depression. Journal of Neurology, Neurosurgery, and Psychiatry, 1960, 23, 56-62.

Hamilton, M. Development of a rating scale for primary depressive illness. British Journal of Psychiatry, 1967, 6, 278-296.

Hamilton, M., \& White, J.M. Clinical syndromes in depressive states. Journal of Mental Science, 1959, 105, 985-998

Hunt, S.M., Singer, K., \& Cobb, S. Components of depression. Archives of General Psychiatry, 1967, 16, 441-446.

Kaiser, H.F. The varimax criterion for analytic rotation in factor analysis. Psychometrika, 1958, 23, 187-200.

Knesevich, J.W., Biggs, J.T., Clayton, P.J., \& Ziegler, V.E. Validity of the Hamilton Rating Scale for Depression. British Journal of Psychiatry, 1977, 131, 49-54.

Mowbray, R.M. The Hamilton Rating Scale for Depression: a factor analysis. Psychological Medicine, 1972, 2 , 272-280.

Nunnally, J. Psychometric Theory, New York: Signet Books, 1968.

Paykel, E.S., Klerman, G.L., \& Prusoff, B.A. Treatment setting and clincial depression. Archives of General Psychiatry, 1970, 22, $11-21$.

Pinzka, C. \& Saunders, D.R. Analytic rotation to simple structure, II: Extension to an oblique solution. Research Bulletin RB-54-31, Princeton: Educational Testing Service, 1954 . 
REFERENCES (continued)

Rose, J.T., Leahy, M.R., Martin, K.A., \& Westhead, T.T. A comparison of nortriptyline and amitriptyline in depression. British Journal of Psychiatry, 1965, 111, 1101-1103.

Rumel, R.J. Understanding factor analysis. Conflict Resolution, 1968, $11,444-480$.

Schwab, J.J., Bialow, M.R., \& Holzer, C.E. A comparison of two rating scales for depression. Journal of Clincal Psychology, 1967, 23, 94-96.

Sorenson, A., \& Stromgren, E. Frequency of depressive states within geographically delimited population groups: 2. Prevalence (the Samsa investigation). Acta Psychiatrica Scandinavica (supplement 162), 1961, 37, 62-68.

Waldron, J. \& Bates, T.J.N. The management of depression in hospital: a comparative trial of desipramine and imipramine. British Journal of Psychiatry, 1965, 111, 511-516.

Ward, C.H., Beck, A.T., Mendelson, C.H., Mock, J.E., \& Erbaugh, J.K. The psychiatric nomenclature: Reasons for disagreement. Archives of General Psychiatry (Chicago), 1962, 7, 198-205.

Wechsler, H., Grosser, G.H., \& Busfield, B.L. The depression rating scale. Archives of General Psychiatry, 1963, 9, 334-335.

Weckowicz, T.E., Cropley, A.J., \& Muir, W. An attempt to replicate the results of a factor analytic study in depressed patients. Journal of Clinical Psychology, 1971, 27, 30-31.

Wrigley, C., Saunders, D.R., \& Newhaus, J.O. Application of quartimax method of rotation to Thurstone's primary abilities study. Psychometrika, 1958, 23, 151-170.

Zung, W. A self-rating depression scale. Archives of General Psychiatry, $1965, \underline{12}, 63-70$. 
SOURCE MATERIAL

Beck, A.T. Depression: Causes and Treatment. Philadelphia: University Press, 1967.

Carney, M.W., Roth, M, \& Garside, R.F. The diagnosis of depressive syndromes and the prediction of ECT response. British Journal of Psychiatry, 1965, 111, 659-674.

Cropley, A.J., \& Weckowicz, T.E. Dimensionality of clinical depression. Australian Journal of Psychology, 1966, 18, 18-25.

Eysenck, H. The classification of depressive illnesses. British Journal of Psychiatry, 1970, 117, 241-250.

Friedman, A.S., Cowlitz, H.W., \& Granick, S. Syndromes and themes of psychotic depression. Archives of General Psychiatry, 1963, 9, 504-509.

Kiloh, L.G., \& Garside, R.F. The independence of neurotic and endogenous depression. British Journal of Psychiatry, 1963, $109,451-463$.

Lorx, M., Sonn, T., \& Katz, M. Toward a definition of depression. Archives of General Psychiatry, 1967, 17, 183-186.

Mendels, J., \& Cochrane, C. The nosology of depression: the endogenous/reactive concept. American Journal of Psychiatry, 1968,124 (supplement), 1-11.

O'Connor, J.P., Stefic, E.C., \& Gresock, C.J. Some patterns of depression. Journal of Clinical Psychology, 1957, 13, 122-125.

Overall, J.E. Dimensions of manifest depression. Journal of Psychiatric Research, 1963, 1, 239-245.

Raskin, A., Schulterbrandt, J., Reatig, N., \& Rice, C.E. Factors of psychopathology in interview, ward behavior, and self-report ratings on hospitalized depressives. Journal of Consulting Psychology, 1967, 31, 270-278.

Raskin, A., Schulterbrandt, J., Reatig, N., \& McKeon, J. Replication of factors of psychopathology in interview, ward behavior, and self-report ratings of hospitalized depressives. Journal of Nervous and Mental Disease, 1969, 148, 87-98.

Rosenthal, S.H., \& Gudeman, J.E. The endogenous depressive pattern. Archives of General Psychiatry, 1967, 16, 241-249. 
SOURCE MATERIAL (continued)

Rosentha1, S.H., \& Klerman, G.L. Content and consistency in the endogenous depressive pattern. British Journal of Psychiatry, $1966,112,471-484$.

Weckowicz, T.E., Muir, W., \& Cropley, A.J. A factor analysis of the Beck Inventory of Depression. Journal of Consulting Psychology, $1967,31,23-28$.

Zung, w. Factors influencing the Self-rating Depression Scale. Archives of General Psychiatry, 1967, 16, 543-547.

Zwaan, E.J. Towards the measurement of depressive states.

Psychiatria, Neurologia, and Neurochirurgia, 1969, 72, 243-248. 


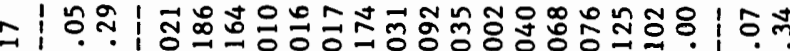

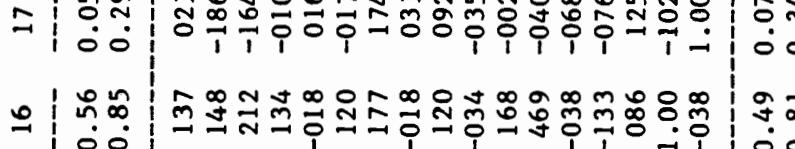

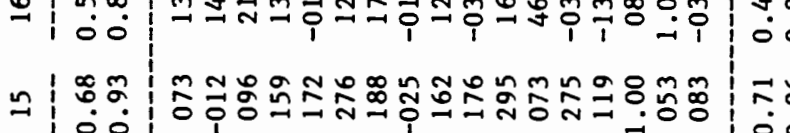

ป

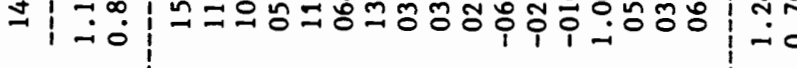

m

₹

ᄀ.

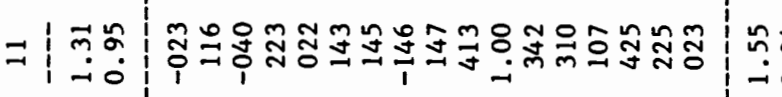

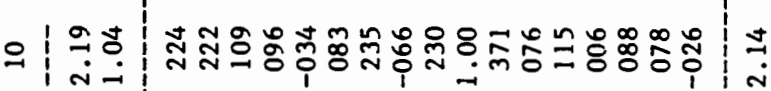

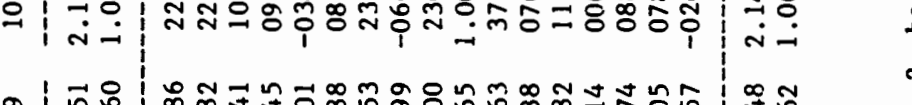

a|

0.

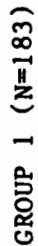

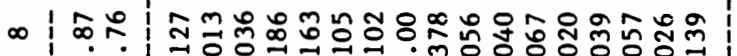

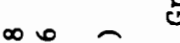

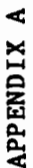

-

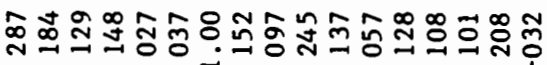
○ं

논

-

No

$\rightarrow \infty$ $1-\infty$

n|

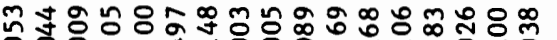

जे

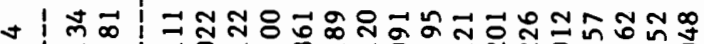

ริะ

- $-\dot{0}$

$m \mid$\begin{tabular}{lll}
$\infty$ & $\infty$ \\
\hdashline & 0 & -1
\end{tabular}

$\stackrel{\infty}{\sim}$

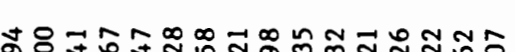

$\therefore 0$

은

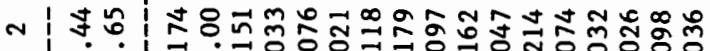

กี่ำ

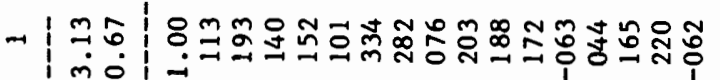

สะ

mio

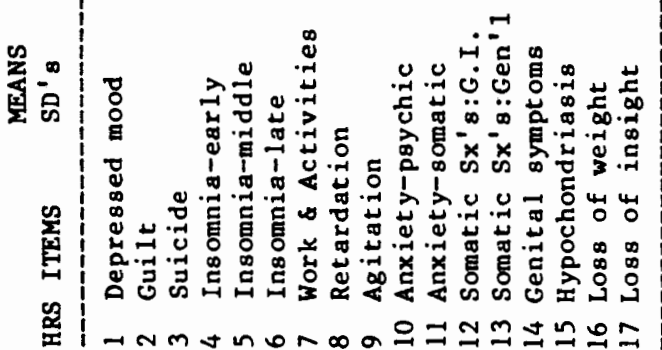

赵央

告 


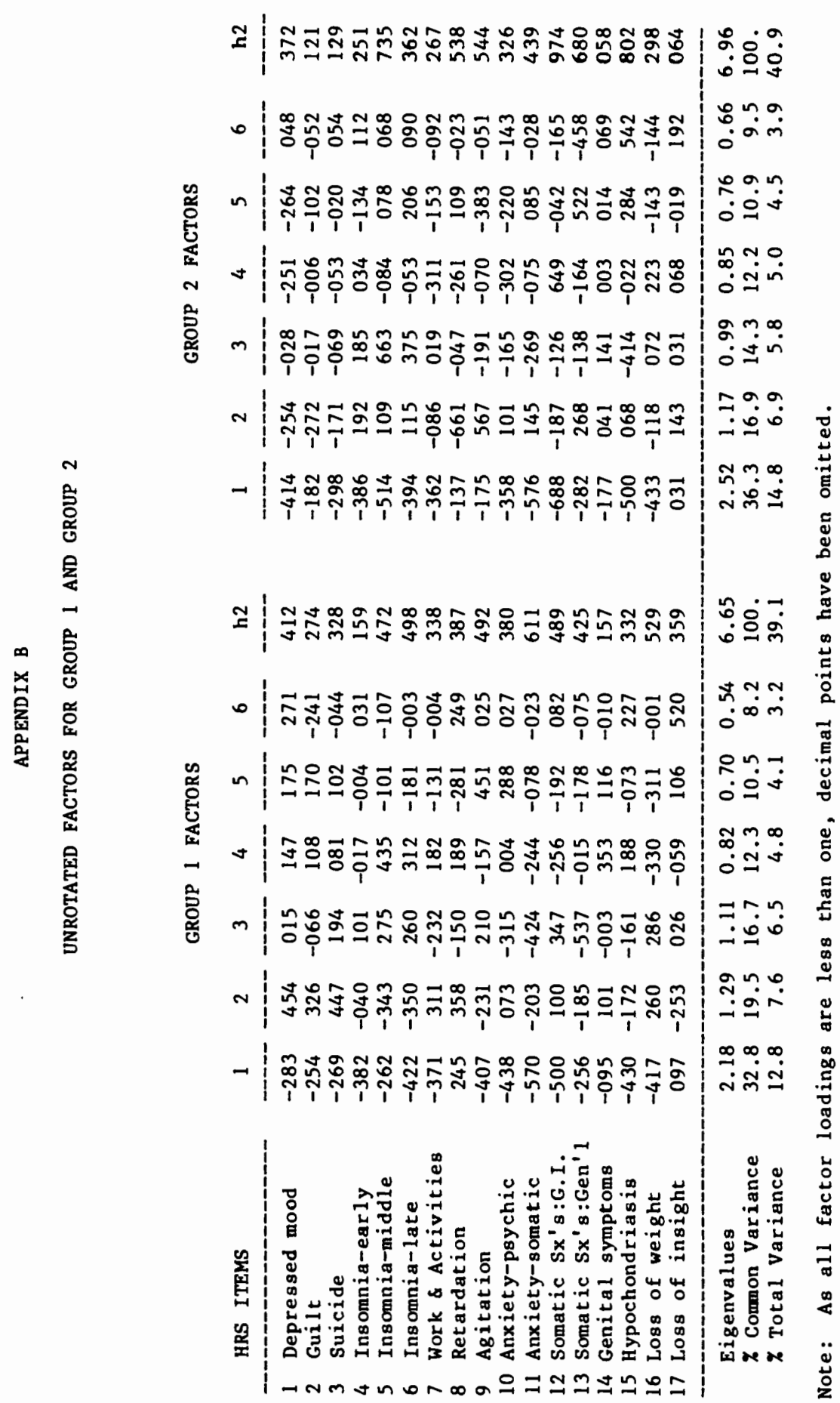




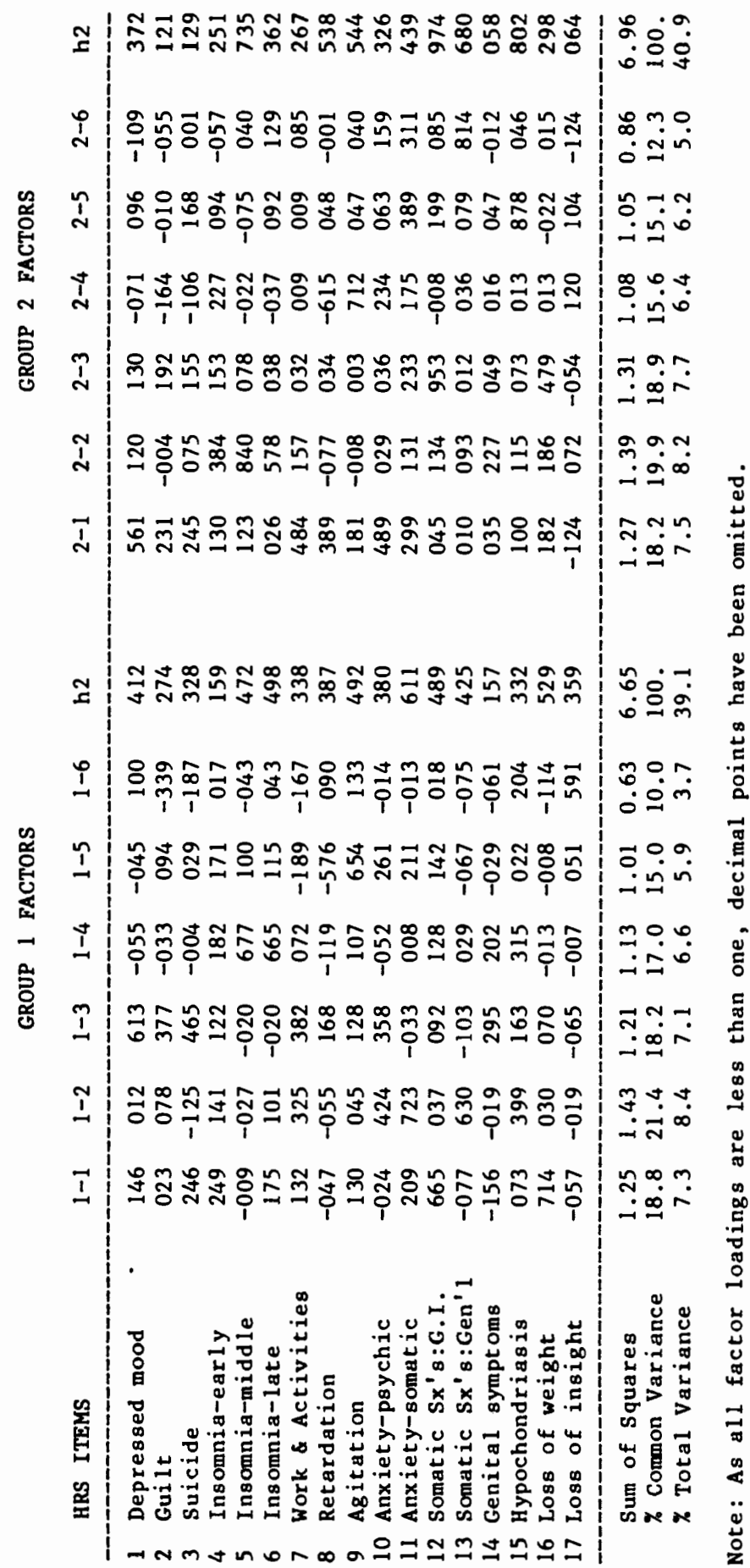




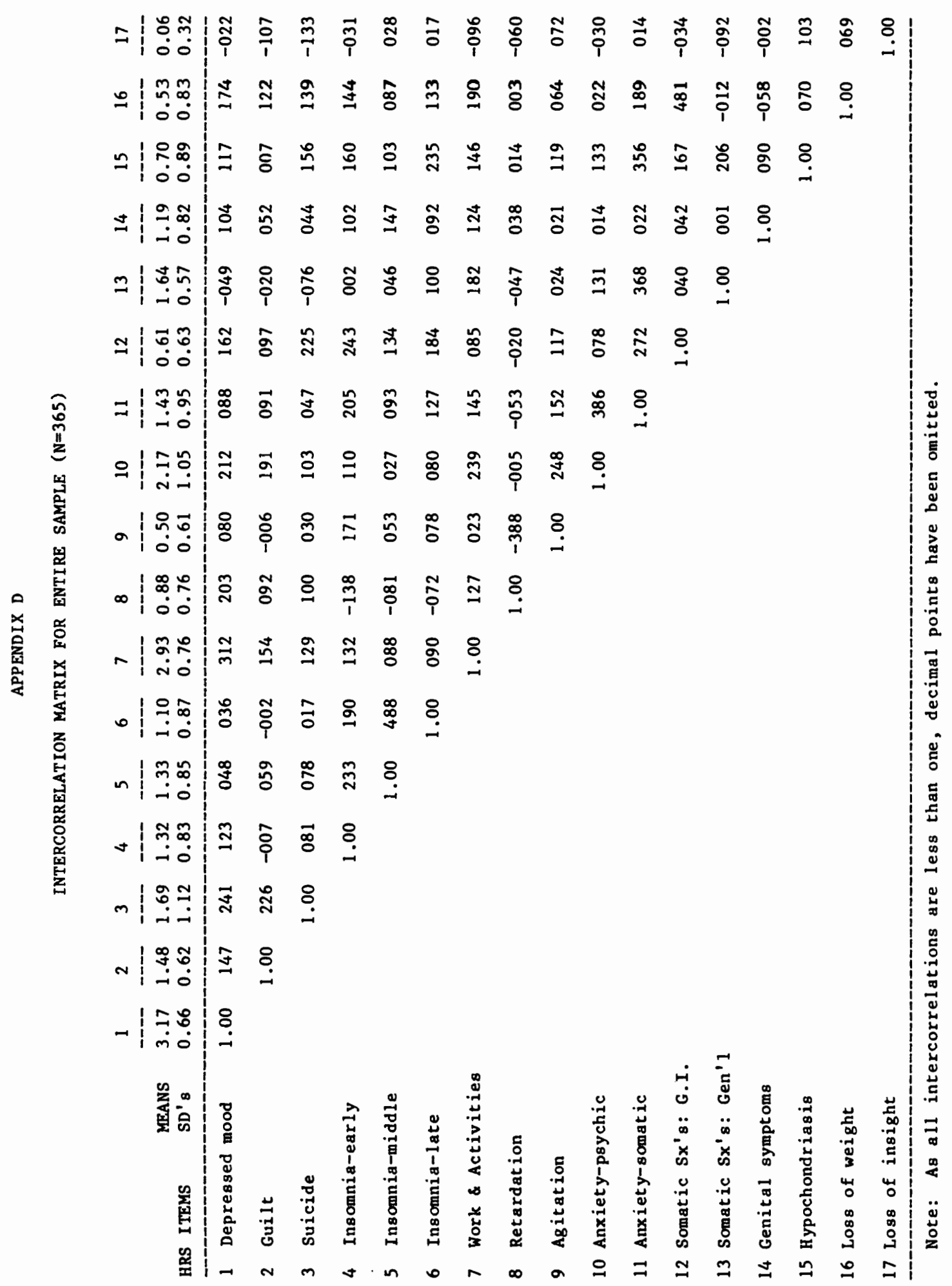




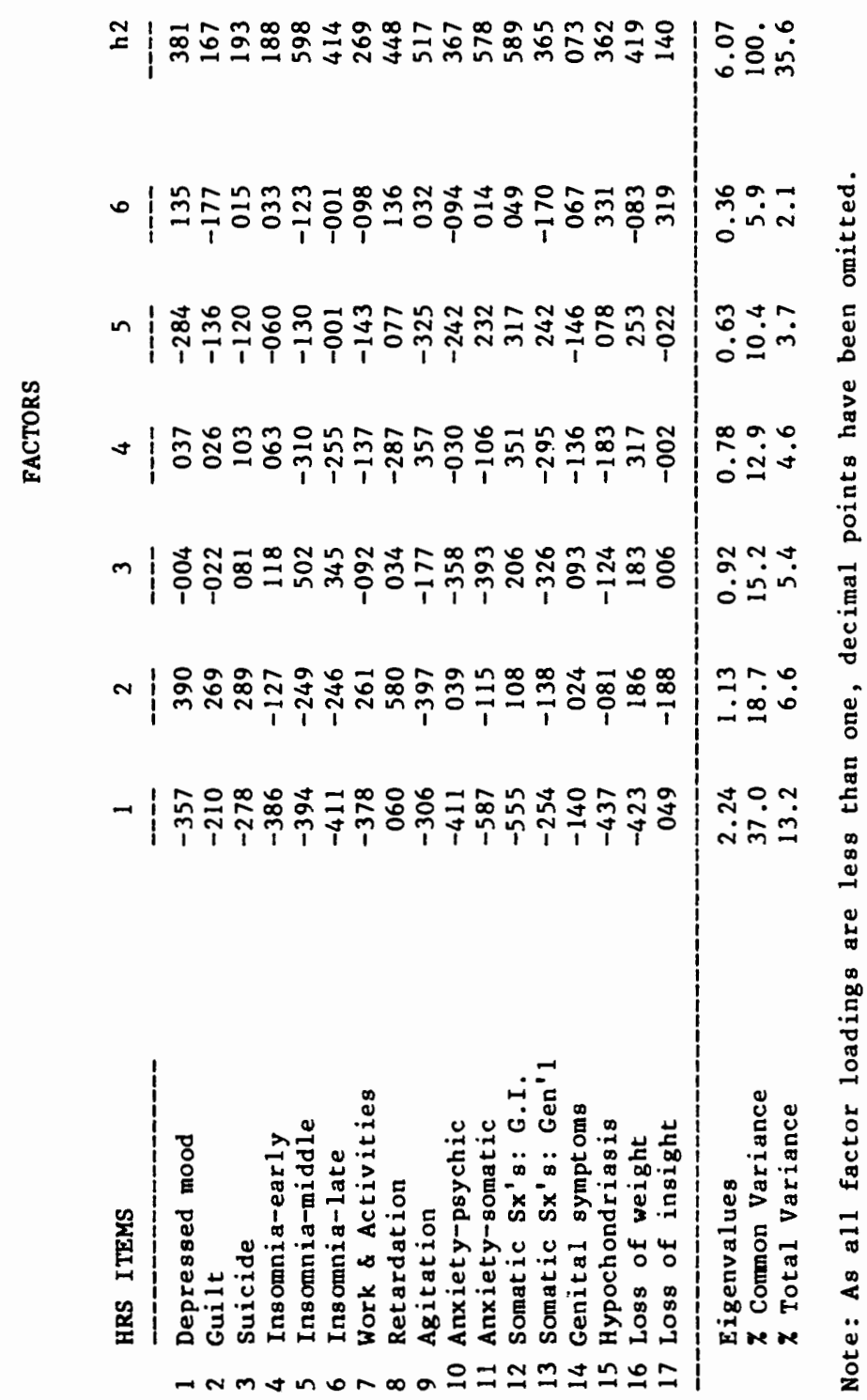




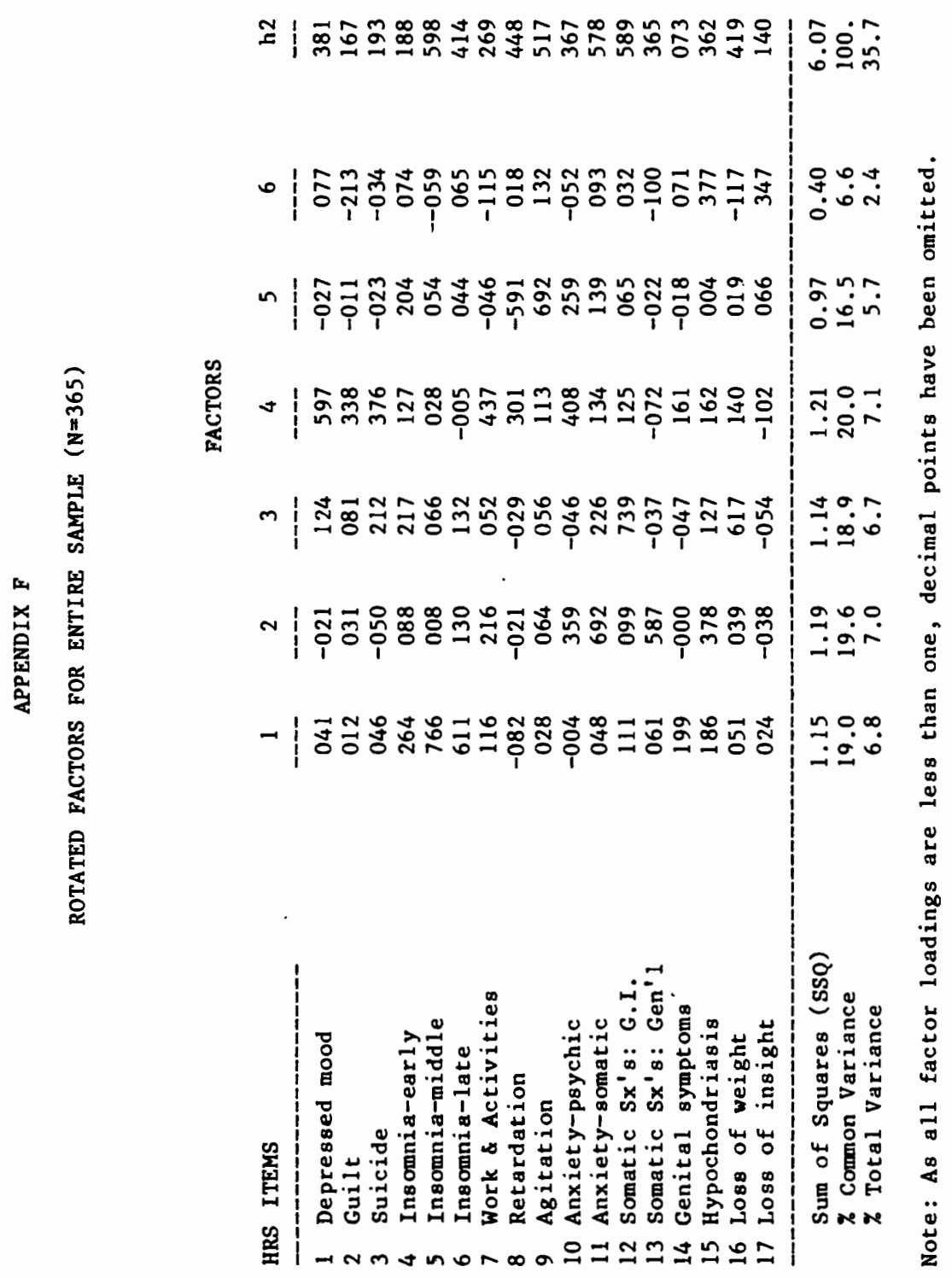

